TECHNICAL REPORT M-68-2

\title{
CONTRIBUTION TO THE MECHANICS OF RIGID WHEELS ON SAND
}

by

K. W. Wiendieck

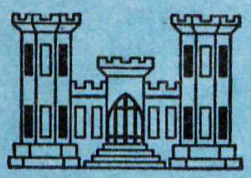

May 1968

Sponsored by

U. S. Army Materiel Command

Conducted by

U. S. Army Engineer Waterways Experiment Station CORPS OF ENGINEERS

Vicksburg, Mississippi

This document is subject to special export controls and each transmittal to. foreign governments or foreign nationals may be made only with prior approval of U. S. Army Materiel Command. 
Destroy this report when no longer needed. Do not return it to the originator.

The findings in this report are not to be construed as an official Department of the Army position, unless so designated by other authorized documents. 


\title{
CONTRIBUTION TO THE MECHANICS OF RIGID WHEELS ON SAND
}

by

K. W. Wiendieck

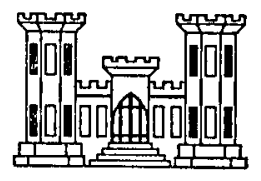

May 1968

\author{
Sponsored by \\ U. S. Army Materiel Command \\ Project No. I-V-0-1450I-B52A \\ Task 01
}

Conducted by

U. S. Army Engineer Waterways Experiment Station CORPS OF ENGINEERS

Vicksburg, Mississippi

ARMY-MRC VICKSBURG. MISS.

This. document" is -subjectwto-speciat export"controls and each"transmittal to foreign-governments* or-foreign-nationals - may wbe.made only with prior -approval of.U. S. Army Materiel Command: 
CONTRIBUTION TO THE MECHANICS OF RIGID WHEETSS ON SAND

\section{Technical Report M-68-2}

May 1968

1. On page 7, line 3, change "crjtical" to "rupture." "r

2. On page 8, in title of fig. 2, raised number should be " 13 ," not " 7. "

3. On page 18, in fig. 9 under "t-DISTRIBUTIONS," change "z" to " $\underline{\text { n" in }}$ all cases.

4. On page 20, line 2 of paragraph 40, insert "the" between "from" and "t $t_{m}$ "

5. On page 21, line 5 below equation 12, change "(fig. 9)" to "(fig. 10)."

6. On page 44, last line, change "fig. 11" to "fig. 14." 
The study reported herein was performed by Dr. Klaus W. Wiendieck of the Mobility Research Branch, Mobility and Environmental ( $M$ and $E$ ) Division, at the U. S. Army Engineer Waterways Experiment Station (WES) as part of the vehicle mobility research program under DA Project No. 1-V-O-14501-B52A, "Research in Earth'Sciences," Task I-V-O-14501-B52A-01, "Terrain Analysis," under the sponsorship and guidance of the Development Directorate, U. S. Army Materiel Command.

The study was conducted during the period January-December 1966 under the general supervision of Messrs. W. J. Turnbull, Technical Assistant for Soils and Environmental Engineering, and.W. G. Shockley and S. J. Knight, Chief and Assistant Chief, $M$ and $\mathbb{E}$ Division; and under the direct supervision of Dr. D. R. Freitag, Chief, Mobility Research Branch, and Mr. A. J. Green, Jr., Chief, Vehicle Dynamics Section, $M$ and $E$ Division. The report was prepared by Dr. Wiendieck.

COE John R. Oswalt, Jr., CE was Director of WES during this study, and $M r . J . B$. Tiffany was Technical Director. 
CONVERSION FACTORS, METRIC TO BRITISH AND BRITISH TO METRIC UNITS

OF MFASUREMENT.

PART I INTRODUCTTON.

Background. . . . . . . . . . . . . . . . . . . . 1

Purpose . . . . . . . . . . . . . . . . . . 2

Scope . . . . . . . . . . . . . . . . . . . 2

PART II: THEORETICAT DEVELOPMENTI . . . . . . . . . . . . . . . I

Review of Theories. . . . . . . . . . . . . . . 4

Applicability of the Shear Stress-Displacement Relations

to Wheels in Sand . . . . . . . . . . . . . . . . .

Brief Outline of Sela's Theory. . . . . . . . . . . . . .

Experimental Ways to Check Theoretical Concepts of Shear/

Normal Stress Ratio . . . . . . . . . . . . . . 13

PART III: TEST RESULTS USED TO IVALUATE THEORIES . • . . . . . . • . 22

PART IV: EVALUATION OF SFIA'S THEORY . . . . . . . . . . . . . 27

Determination of the $t_{m}$ Values Using Sela's Theory. . . . . . 27

Theoretical and Experimental Results Compared Using

Sela's Theory . . . . . . . . . . . . . . . . . 29

Discussion of Results Obtained by Sela. . . . . . . . . . 32

Validity of Any Shear Stress Relation . . . . . . . . . . 32

PART V: PROPOSED NEW CONCEPT . . . . . . . . . . . . . . . . . . 34

Development of Concept. ... . . . . . . . . . . . 34

Theoretical and Experimental Results Compared Using

New Concept........................ 44

Comparison of New Concept and Sela's Approach . . . . . . . 47

PART VI: CONCLUSIONS AND RFCOMMFINDATIONS . . . . . . . . . . . . . $5 I$

Conclusions . . . . . . . . . . . . . . . . . 51

Recommendations . . . . . . . . . . . . . . . 51

IITERATURE CITED. . . . . . . . . . . . . . . . . . . . 52

TABLE 1 



\title{
NOTATION
}

\author{
A toxperimental coefficient, dimensionless \\ b Wheel width, cm \\ c Cohesion, $\mathrm{N} / \mathrm{cm}^{2}$ \\ $G$ Penetration resistance gradient, $\mathrm{N} / \mathrm{cm}^{3}$ \\ I Instantaneous center of rotation \\ $j$ Displacement or distortion, in.* \\ $k$ Horizontal soil deformation module, $\mathrm{cm}$ or in. \\ $k_{c}$ Cohesive modulus of sinkage, $1 b / i n$. \\ $k_{\varnothing}$ Friction modulus of sinkage, Ib/in. $(2+n)$ \\ $\ell_{L}, \ell_{B}, \ell_{F}$ \\ Lengths of lunule zone, bulldozing zone, and zone of lateral \\ flow, respectively, cm \\ m Factor of proportionality, dimensionless \\ M Torque, $\mathrm{cm}-\mathrm{N}$ \\ n Sinkage exponent, dimensionless \\ $\mathrm{R}$ Wheel radius, $\mathrm{cm}$ \\ s Slip, percent \\ $t$ Shear-to-normal stress ratio, dimensionless \\ $t_{m}$ Mean shear-to-normal stress ratio, dimensionless \\ $\mathrm{v} \quad$ Sliding velocity, $\mathrm{cm} / \mathrm{sec}$ \\ $\mathrm{W}_{\mathrm{L}}, \mathrm{W}_{\mathrm{B}}, \mathrm{W}_{\mathrm{F}}$ Widths of lunule zone, bulldozing zone, and zone of lateral \\ flow, respectively, $\mathrm{cm}$ \\ W Wheel load, $\mathbb{N}$ \\ $x$ Distance from the leading edge to a considered point on the \\ wheel-soil interface, in.
}

* The dimensions inches and pounds refer to formulas quoted from AngloSaxon literature (see Conversion Factor table on page ix). All expressions pertaining properly to this report are in the metric system. 
y Coordinates across the wheel-soil interface, measured from the center line, $\mathrm{cm}$

z Sinkage, $\mathrm{cm}$

$\alpha$ Angle at the wheel center between the leading edge of the wheel-soil interface and the vertical reference line, deg or radians

$\alpha_{d}$ Angle designating the separation point between bulldozing and trailing zone, according to Sela's theory, deg

$\beta$ Angle at the wheel center between the trailing edge of the wheel-soil interface and the vertical reference'line, deg or radians

$\gamma$ Inclination of the shear stress vector against the vertical. plane of travel, deg

$\delta$ Position angle, angular coordinate, radians

$\lambda$ Experimental constant, dimensionless

o Tangential or shear stress, $\mathrm{N} / \mathrm{cm}^{2}$

$\tau$ Normal or radial stress, $\mathrm{N} / \mathrm{cm}^{2}$

$\varnothing \quad$ Angle of internal friction, deg 
CONVERSION FACTORS, METRIC TO BRITISH AND BRITISH TO

METRIC UNITS OF MEASUREMENT

Metric units of measurement used in this report can be converted to British units as follows:

Multiply

centimeters

meters

Newtons

Newtons per square centimeter

penetration resistance gradient

in Newtons per cubic centimeter
By

$0.3937 \quad$ inches

3.2808 feet

$0.2250 \quad$ pounds

1.4503 pounds per square inch

$11.0253 \quad 0-6$ in. cone index
To Obtain

British units of measurement used in this report can be converted to metric units as follows:

\begin{tabular}{|c|c|c|}
\hline Multiply & By & To Obtain \\
\hline inches & 2.54 & centimeters \\
\hline pounds & 4.444 & Newtons \\
\hline pounds per square inch & 0.689476 & Newtons per square centimeter \\
\hline
\end{tabular}



SUMMARY

Current theoretical concepts of the soil-running gear interaction are based on empirical pressure-sinkage and shear stress-displacement relations. It was found that the tests from which these relations were obtained present a poor analogy, at best, to the soil-running gear interaction. In particular, the use of the shear stress-displacement relation for an analytical evaluation of the shear stresses at the contact surface of rigid wheels on sand was found to be misleading, primarily because equations obtained by the bevameter or dragged plate tests describe the soil behavior in the intermediate state, which is a state between the elastic and plastic states. Recent publications point out that part of the soil in the immediate vicinity of a powered wheel is in a state of. actual plastic flow and part is in a quasielastic state. Thus, the soilbevameter interaction is of a fundamentally different nature than the soil-wheel interaction which makes results of such tests unsuitable for predicting wheel performance.

Sela's theory of the relation between a rigid wheel and dry sand is based exclusively on the shear stress-displacement concept, and thus provided an excellent means of checking the concept as a whole. Using a simple approximate relation between the $\mathrm{M} / \mathrm{RW}$ ratio and the mean shearto-normal stress ratio $(\tau / \sigma)$ taken over the total contact surface, the theory was checked by means of constant-slip rigid wheel tests. The experimental findings strongly supported the conclusion that shear stressdisplacement relations are irrelevant to soil-wheel mechanics.

A new theory was developed that attempts to assess the variation of $\tau / \sigma$ along the soil-wheel interface, without referring to shear stressdisplacement relations. The proposed theory uses recent investigations of the soil rupture pattern beneath rigid wheels on cohesionless material as the basis for subdividing the total soil-wheel interface into three zones of different soil behavior. Simple assumptions then are made of the soilto-wheel movements within these zones to evaluate $\tau / \sigma$. The approach developed herein was checked against experimental results and was in much better agreement with the test data than were previously developed theories. 


\section{PART I: INTRODUCTION}

\section{Background}

1. The forces that move an earthbound vehicle over the ground are, in the last analysis, soil reaction forces. The engine serves only to generate these soil reactions by transmitting a certain mechanical energy to the running gear. Recognition of this fact makes the interaction between the soil and the running gear the key problem of theoretical vehicle-soil mechanics.

2. Current theoretical approaches to this fundamental problem are based essentially on the idea of stress-displacement relations for soils. The most commonly used are the pressure-sinkage relation expressed by the equation

$$
\sigma=\left(\frac{k_{c}}{b}+k_{\phi}\right) z^{n}
$$

and the shear stress-displacement relation

$$
\tau=(c+\sigma \tan \varnothing)\left(I-e^{-j / k}\right)=\tau_{\max }\left(I-e^{-j / k}\right)
$$

Both expressions have been proposed by Bekker, ${ }^{1}$ the latter in a somewhat more complex form to account for peak shear stresses. Equation 2 as given here is a simplification introduced by Janosi and Hanamoto. 2

3. Although it is obvious from the manner of derivation that these equations are simply mathematical formulations of experimental curves obtained under special conditions, certain researchers have tended to consider them as laws of the material. Reference to these equations as "stress-strain relations for soils" or to some of the parameters as "soil constants" has encouraged this tendency.

4. The relations stated in equations 1 and 2 , or similar ones, are not used in soil mechanics, despite the fact that knowledge of the 
stress-strain characteristics for soils is highly desirable for many soil mechanics problems. Because the problems involved are important, and because the concept is new, stress-strain relations for soils should have been considered with studious caution. However, it appears that these relations, or their basic ideas, were accepted immediately by most research workers in the field of terrain-vehicle mechanics. Most of the literature on this subject is related to secondary issues such as curve-fitting techniques, form and size of test equipment, establishment of a definite set of "soil constants," and more or less far-reaching modifications of the analytical expressions. The main issue-whether these relations are applicable at all in the field of soil-vehicle mechanics--has rarely been questioned seriously.

\section{Purpose}

5. The purpose of this study was threefold:

a. To critically examine the shear stress-displacement relations for soils and determine whether these relations are applicable to wheels on cohesionless soils.

b. To develop new means of experimentally examining any theory on the ratio of shear-to-normal stress at the wheel-soil interface, since present methods are not very reliable.

c. To develop a theoretical concept regarding the shear-tonormal stress ratio at the wheel-soil interface.

In a more general sense, the purpose of this study was to stimulate a cxitical reexamination of the broadly accepted stress-displacement relations.

\section{Scope}

6. Both a theoretical and an experimental approach were used in this study to investigate the distribution of the tangential-to-normal stress ratio along the wheel-soil interface of rigid wheels in sand. The experimental portion included constant-slip tests in sand using two rigid. wheels instrumented to measure tangential and normal stresses at the 
wheel-soil interface, and the length of the interface (contact length). Wheel load and width, soil strength, and slip were varied to determine their effects on magnitudes and variations of the stresses, as well as on the performance of the wheel. Emphasis was placed on correctly determining the $\mathrm{M} / \mathrm{RW}$ ratio as a function of contact length. The influence of the shear stress and normal stress distribution on the characteristic $\mathrm{M} / \mathrm{RW}$ ratio was evaluated with a calculation performed by computer. 


\section{Review of Theories}

7. It must be emphasized that specific stress-strain relations for soil are not yet established. 3 It was not until very recently that first steps were taken by soil mechanics researchers to develop theoretically founded stress-strain relations for soils, in the sense of a constitutive relation of the material, because of the formidable difficulties inherent in such investigations.

8. In soil mechanics, the soil is generally idealized and assumed to behave like an elastic or plastic material or according to some other constitutive relation, such as viscoelasticity. It has been claimed that this approach is inadequate in soil-vehicle mechanics; that a "new approach is needed to relate vertical soil deformation to ground pressure and horizontal soil deformation to shear strength. "4 It will be shown later that this new approach aims primarily at a stress domain where the soil is somewhere between the elastic and the plastic state.

9. Another "in between" aspect of the problem was pointed out by Deresiewicz, ${ }^{5}$ who attributed to granular aggregates a state of matter between the solid and the liquid state. If this is correct, it certainly presents additional difficulties to the solution.

10. The development of specific stress-strain relations for soils seems possible only from a thorough theoretical approach that takes into account the discrete, noncontinuous character of the material. Such a "physics of granular aggregates" has recently been claimed by Kézdi, 6 and basic research along this line already has been started.

11. Besides Deresiewicz's review of previous work on this matter, there are other recent contributions generally characterized by the attempt to take the necessary step from regular packings of spheres to random arrangements of odd-shaped particles. Green and Rivlin7 attempted to relate the mechanics of structured materials to that of continuous media by introducing the notion of multipolar vector fields. Litwiniszyn obtained a fairly accurate description of sand deformations under certain conditions 
of flow by considering the discrete movement of particles as a stochastic process. (Berry ${ }^{8}$ gives a discussion of and complete reference for

Litwiniszyn's work.) Murayama9 considered the probability of finite grain-to-grain sliding in the so-called elastic state and thus explained the relatively low values of Young's modulus for sands. Starting from simple assumptions based on the statistical force distribution for particulate matter, Smoltczyk ${ }^{10}$ developed a theoretical approach to the problem of earth pressures prior to the state of failure (intermediate state) that may become a link between the given elastic state at rest and the state of plastic failure. Wiendieck ${ }^{11}$ investigated the structure of granular media from a statistical point of view.

12. These investigations demonstrate the multiple problems that have yet to be overcome. Once a thorough understanding of the internal deformation mechanism for irregular aggregates is gained, perhaps stressstrain relations can be established by integrating the elementary process over a certain volume. Meantime, the quoted stress-displacement relations (equations 1 and 2) must be taken for what they are: analytically expressed test results, with no theoretical foundation.

\section{Applicability of the Shear Stress-Displacement} Relations to Wheels in Sand

13. In a comparative study, wills 4 found that the general form of the shear stress-displacement curve for sand obtained with a torsional ring shear apparatus differed significantly from that obtained with a Iinear shear apparatus, but that the form of the curve is not dependent on size for either device. He further noted that the methods (he mentions three) used to analyze these curves are highly subjective and do not always yield comparable results. For instance, in a given case, the ratios of corresponding "horizontal soil deformation moduli $k$ " varied from $1: 2$ to 2:1, and the absolute magnitude of the modulus obtained for a given device depended strongly on the curve-fitting technique applied. The values are as follows: 


\begin{tabular}{|c|c|c|c|}
\hline $\begin{array}{l}\text { Method of } \\
\text { Analysis }\end{array}$ & $\begin{array}{l}\text { Ring Shear } \\
\text { Apparatus, } k_{a}\end{array}$ & $\begin{array}{l}\text { Linear Shear } \\
\text { Apparatus, } \mathrm{k}_{\ell}\end{array}$ & $\begin{array}{l}\text { Ratio } \\
\mathrm{k}_{\ell} / \mathrm{k}_{\mathrm{a}}\end{array}$ \\
\hline Bekker & $1-1 / 2$ & $3 / 4$ & $1: 2$ \\
\hline Janosi & $1 / 4$ & $1 / 2$ & $2: 1$ \\
\hline Adams & $1-1 / 2$ & $3 / 4$ & $1: 2$ \\
\hline
\end{tabular}

Equally contradictory results are obtained when ring shear and linear test results axe compared using the same curve-fitting techniques. This contradiction is remarkable in that the results are from pure, although slightly different, sliding processes.

14. In view of these data, the application of shear stressdeformation relations to wheels can hardly be defended, since the action of a rolling wheel on the soil is far from being a pure sliding. Their inapplicability is emphasized by closely examining the physical process that occurs in the sand under a wheel and a sliding device, respectively.

15. A typical shear stress-displacement curve obtained from a horizontally dragged plate test is shown in fig. 1.* During such a test,

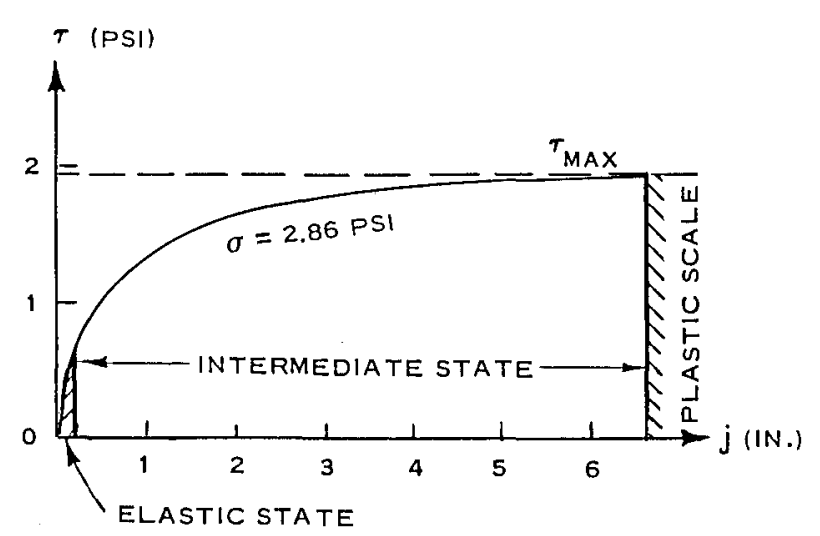

Fig. 1. Shear stress-displacement relation obtained with linear apparatus 12 the soil apparently is transformed from a presumably elastic state at rest into a perfect plastic condition, once the horizontal asymptote is reached. The aim of the test was to explore not the elastic or plastic states, but the undefined state between, which will be called the intermediate state in this report. This process of transformation necessarily is accompanied by the progressive forming of a certain pattern of rupture surfaces within the soil. There is no pattern for the elastic condition; there is a completely formed one for the plastic condition. 16. What does a partially developed rupture pattern look like? It might be called an incipient rupture pattern, which has some resemblance

* A table for converting British units (such as those used in fig. 1) to metric units is given on page ix. 
to the definite pattern of the plastic state into which it develops. The main feature of both the definite and incipient rupture patterns is a horizontal extieal surface somewhere beneath the dragged plate, probably immediately under the plate or along its grouser tips, when the plate is provided with them. Reece 12 assumed two inclined rupture surfaces that, together with the plate, confine a triangular soil wedge. This assimption has no bearing on the following discussion, in which a horizontal rupture surface was assumed for the sake of simplicity. The notion of stresses, as applied in equation 2, certainly refers to a horizontal rupture surface.

17. When a sliding device is applied to the soil, shear stresses at the incipient horizontal rupture surface build up gradually from zero to $\tau_{\max }$ as the soil progresses from the elastic condition, through an undefined intermediate state, to the plastic condition. For the shear stress-displacement relation to apply to wheels, it is necessary, therefore, that:

a. The wheel-soil interface be an incipient rupture surface.

b. The soil in the immediate vicinity of the interface be in neither a plastic nor an elastic state, but in an intermediate one.*

18. Boucherie ${ }^{13}$ showed, in recent investigations, that precisely the contrary happened under a rigid wheel moving on an artificial twodimensional granular medium formed by a random packaging of aluminum rolls (Schneebeli model). A rigid wheel rolling at approximately 13 percent slip is shown in fig. 2, and a schematic diagram of the phenomenon in fig. 3. At the forward part of the interface, the bow wave can be recognized. The soil within the bow wave is certainly in a perfect plastic condition. The trajectories of the soil particles at the interface are almost perpendicular to it, thus the rolling surface of the wheel in this region is assumed to be a real rupture surface.

19. At the rearward end of the interface, a moon-shaped part of the

* Perfect plastic zones and real rupture lines could only appear at the end of a long, intermediate process, i.e. when the contact surface is long enough to permit the soil to reach plasticity. The statements hold, therefore, at least for the main part of the contact zone. 


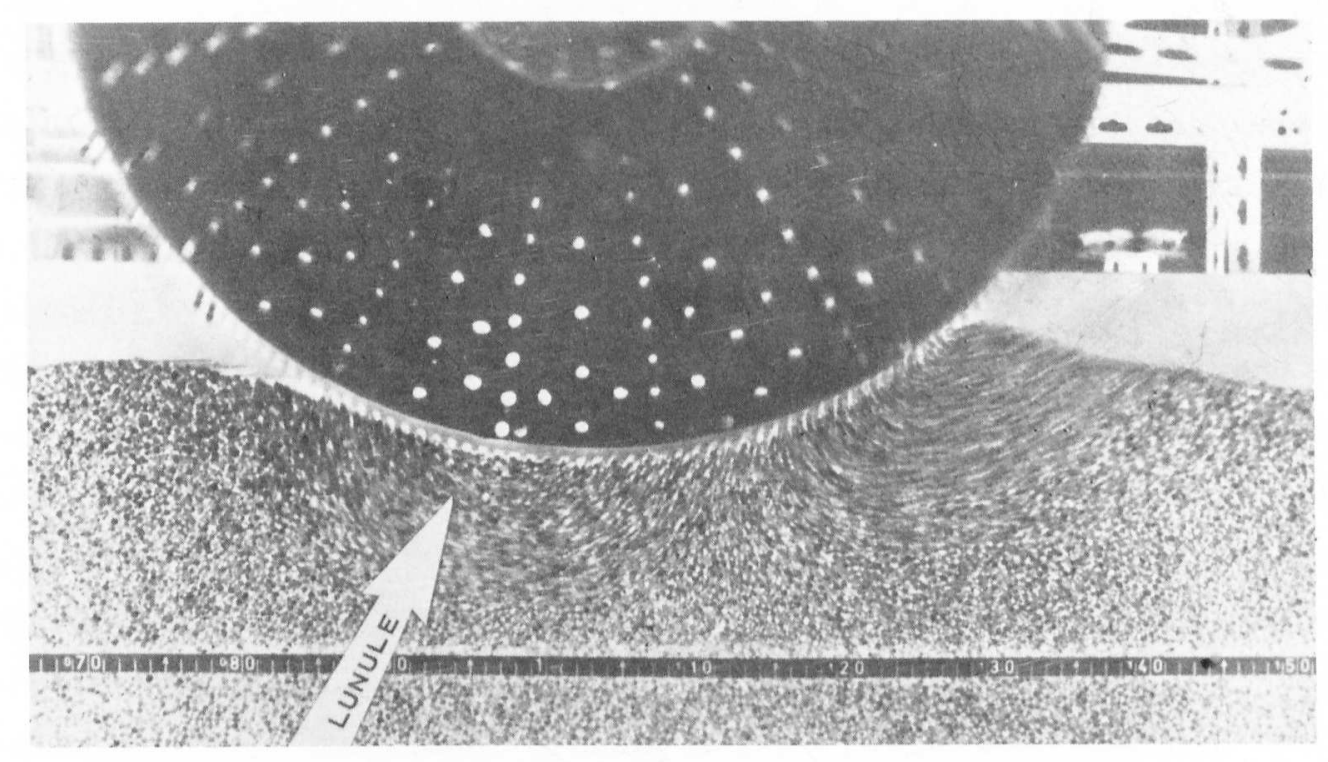

Fig. 2. Rupture pattern beneath rigid wheels $7 / 3$

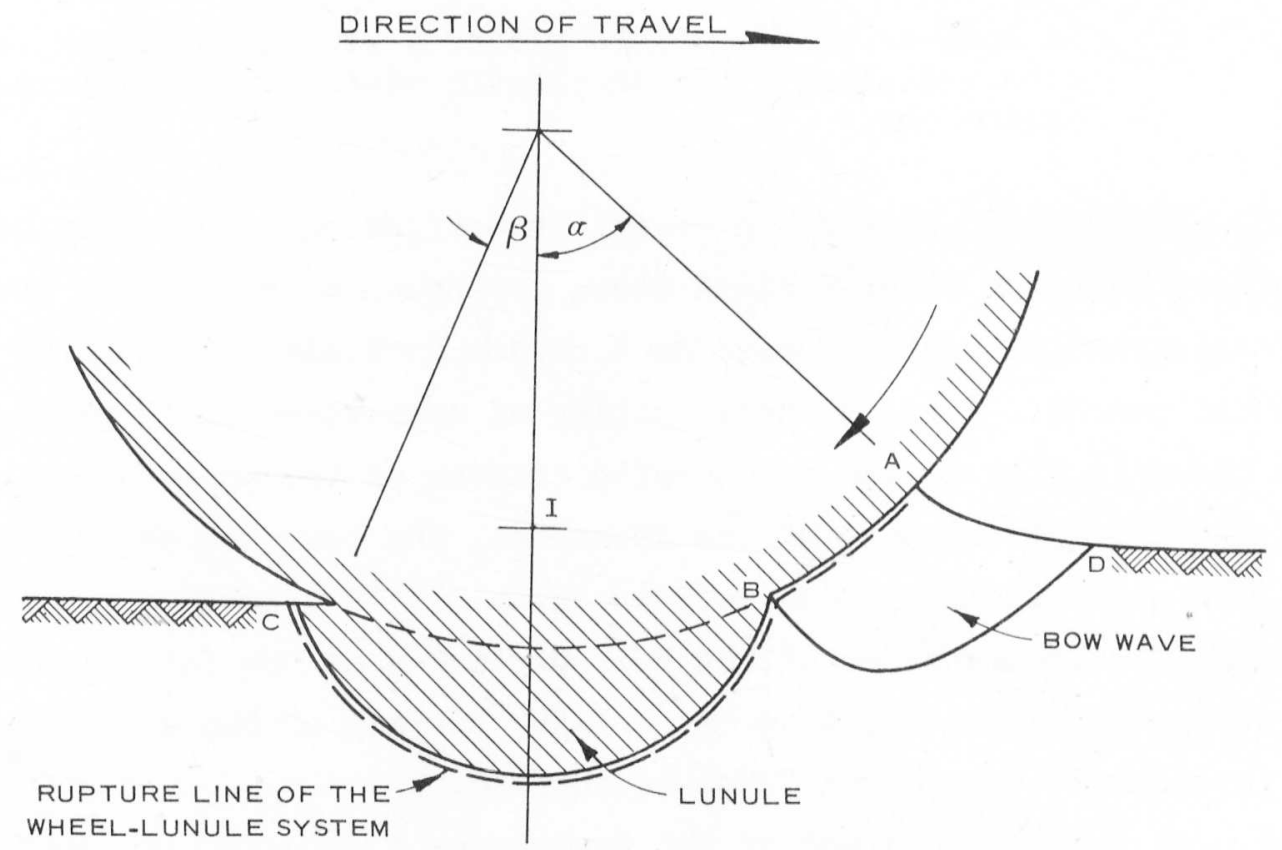

Fig. 3. Schema of rupture pattern beneath rigid wheels 
soil, which has been termed "Iunule," seems to be solidly attached to the wheel and to turn around the instantaneous center of rotation together with the wheel. Although the individual soil particles in the formation of the lunule change constantly as the wheel moves forward, it seems that the instantaneous existing lunule behaves like a solid body. Hence, the soil along the contact zone within the domain of the lunule has to be considered. in an elastic state, which means that the wheel-soil. interface within the domain of the lunule is not a rupture surface.

20. This general schema is valid through the whole positive slip range; only the relative proportions of the two regions change. At zero slip, the forward bulldozing zone is predominant; at 100 percent slip, the outer limit of the Iunule coincides with the wheel circumference, thus covering the total contact length. Although Boucherie's experimental study was only two-dimensional, there is no reason to doubt that the same general pattern of soil kinematics exists under an actual wheel. This is confirmed by recent research by Wong and Reece, 14 who made photographic studies similar to Boucherie's of the soil movements beneath a wheel, but used an actual sand fill, rather than an artificial medium. These investigations showed that the pattern under an actual wheel is the same as the one shown in figs. 2 and 3 .

21. Since no proof has been given that the lunule behaves like an elastic solid, it might be argued that the soil in this region is in the intermediate state. However, this would require that the intermediate state develop behind the plastic state (measured from the leading edge of the wheel-soil interface) which contradicts the way shear stressdisplacement relations are usually applied.

22. The existence of quasisolid soil masses attached to rigid elements moving into or through cohesionless soils is well known in soil mechanics. Biarez 15 observed such rigid, nondeforming soil bodies in almost all of his investigations of various models of construction elements in the plastic soil condition and demonstrated it using a special photographic technique that allowed the camera to move with the element. The general shape of the soil bodies was determined by the conditions of 
kinematic compatibility, while their actual size seemed to be such that the effort needed to move the elements was.a minimum.

23. A pivoting pile bears a striking resemblance to the wheel problem. As shown in fig. 4, a ball-socket kind of hinge develops in the lower

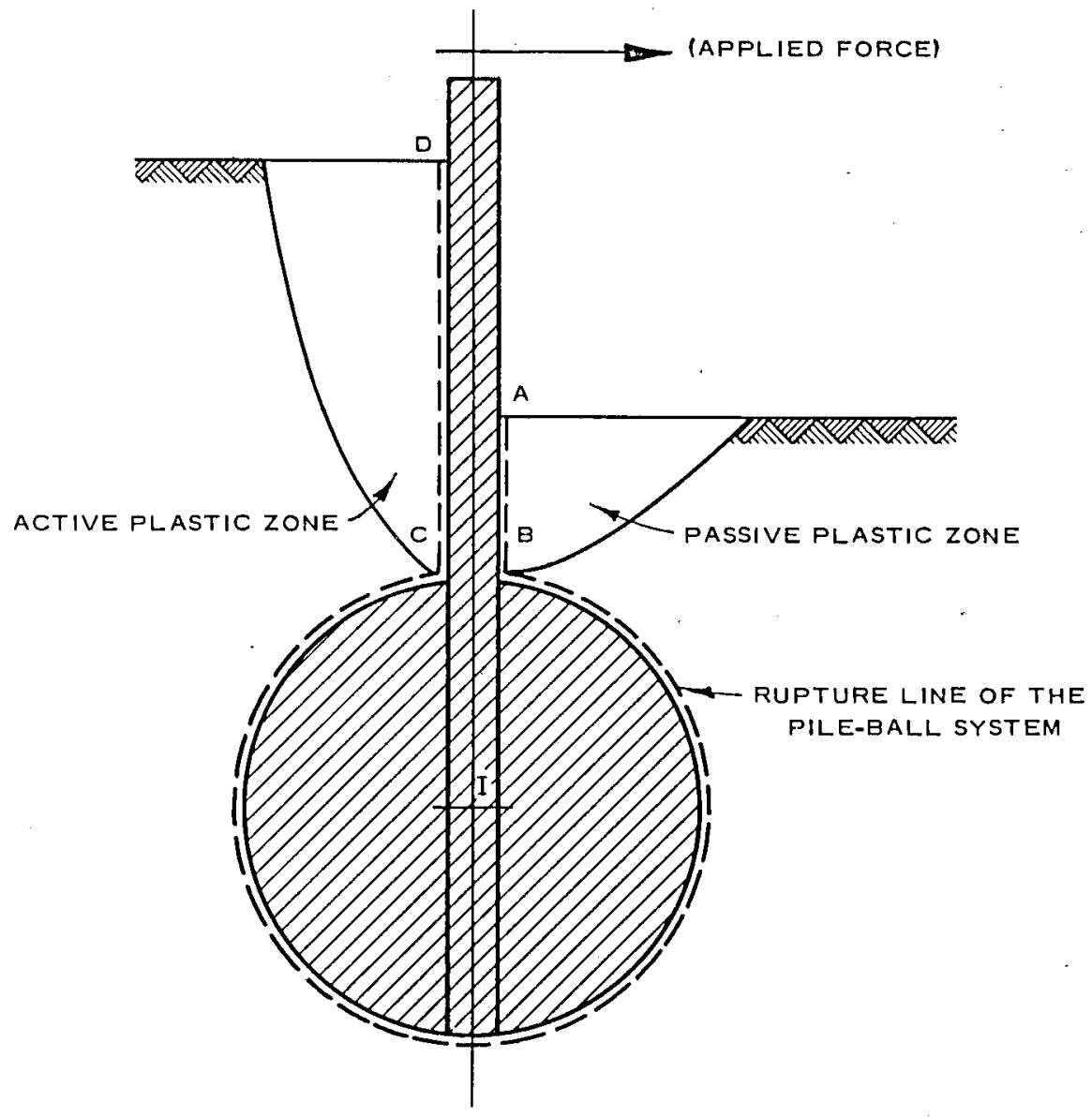

Fig. 4. Pivoting pile showing ball-socket hinge part of the medium and has the same function as the lunule, i.e., to make its rotation kinematically possible and/or to facilitate the rotation around the instantaneous center of rotation. Plastic soil masses appear only in the upper part of the medium. This schema, in combination with the principle of minimum energy or rotation, was used in a new approach ${ }^{16}$ to the stability of sheet pile walls and matched the results of model tests better than previous theories.

24. A similar approach to the mechanics of a rolling wheel might clarify some open questions. But before this can be undertaken, some light must be shed on the stress distribution along the line ABC in fig. 3 . The apparently rigid lunule might then appear as a key feature of the kinematics of wheel movement.

25. From the foregoing ( see paragraph 17), it can be stated that: a. A rupture surface occurring at the wheel-soil interface is fully developed. 
b. The soil along the interface beneath a rigid wheel is either in a state of perfect plastic flow (bulldozing) or in a quasielastic state (Iunule).

Clearly, these conditions do not meet the theoretical requirements implied by the use of equation 2 .

26. It has been demonstrated that the action of a wheel upon cohesionless soil is completely different from that of sliding devices. The shear stress-displacement equation, therefore, cannot be applied to wheels in sand.

\section{Brief Outline of Sela's Theory}

27. Sela's theory 17 is based entirely on the concept of shear stressdisplacement relations, and, as such, provides an excellent opportunity to check the basic theoretical concept.

28. For cohesionless soils $(c=0)$, equation 2 may be rewritten:

$$
t=\frac{\tau}{\sigma}=\tan \phi\left(1-e^{-j / k}\right)
$$

Usually applied to wheels or tracks

$$
j=x s
$$

based on the assumption that "the distortion $j$ might be expressed as a product of $\operatorname{slip}(s)$ and the distance $(x)$ measured from the beginning of the contact area to the place where the shearing strength of the soil is developed."1 Expressed in radians (see fig. 8, page 17)

$$
x=R(\alpha-\delta)
$$

Accordingly:

$$
t=\frac{\tau}{\sigma}=\tan \phi\left[1-e^{-R(\alpha-\delta) s / k}\right]
$$

29. Sela ${ }^{17}$ refined equation 6 to take into account the effect of the 
bow wave, but neglected lateral flow. For the bow wave zone he proposed the equation

$$
t=\frac{\tau}{\sigma}=\tan \phi\left\{I-e^{-R\left[(\alpha-\delta)_{s}+\left(\delta-\alpha_{\alpha}\right) m\right] / k}\right\}
$$

where the angle $\alpha_{d}$ designates the separation point between the bow wave region (as defined by Sela) and the rear part of the interface, and $m$ is a factor of proportionality. The angle $\alpha_{d}$ is defined by the relation

$$
\tan \alpha_{d}=\frac{\tau}{\sigma}=\tan \phi\left[1-e^{-R\left(\alpha_{d}-\delta\right) s / k}\right]
$$

30. An example of the resulting theoretical $\tau / \sigma$ curve, together with the experimental measurements made with pressure cells, is reproduced from Sela's work ${ }^{17}$ in fig. 5. According to Sela's theory, the variation
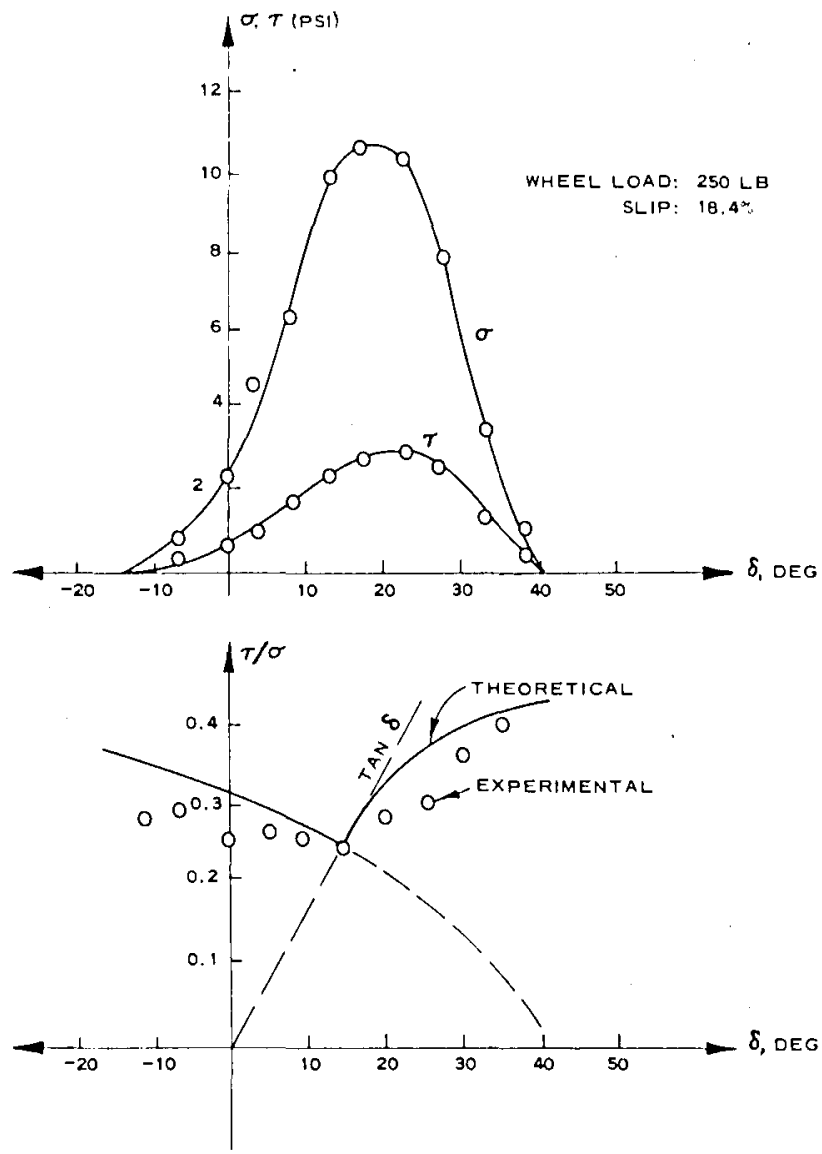

Fig. 5. $\tau / \sigma$ measurements using Sela's theory 
of the $\tau / \sigma$ ratio over the contact length is generally characterized by an increase toward both ends of the wheel-soil interface, with the lowest value at the point of separation between the forward bulldozing and the rearward trailing zone.

\section{Experimental Ways to Check Theoretical Concepts}

of Shear/Normal Stress Ratio

Tangential and normal

pressure cell recordings

31. To use this method, a set of carefully calibrated and protected pressure cells, placed flush with the rolling surface of the wheel, records the tangential and normal stresses as the wheel surface moves through the soil. Selal7 used this method to check his theoretical concept and found that the general shapes of the distribution curves for the measured and predicted variation of the $\tau / \sigma$ ratio matched reasonably well.

32. However, pressure cell recordings are not completely reliable, since neither the influence of the protective membrane necessary to prevent sand wedging against the cell nor the possible arching effects are known. In WES tests using cell recordings, discontinuous rupture phenomena in the sand caused considerable vibration of the wheel that made the recorded stress curves completely unreadable in some instances. The tangential stress records were affected more severely, and the degree of disturbance seemed to increase as slip, soil strength, and load increased. When actual $\tau$ and $\sigma$ readings were used to determine the pertinent $\tau / \sigma$ ratios, an enormous scatter resulted (see figs. 6 and $7^{*}$ ). The data scatter can be reduced either by smoothing the original curves by hand or by electronically filtering the signals from the pressure cells. The first method introduces subjective personal judgment; the second usually

* In these figures, some of the most scattered points are not shown. To obtain some representable results in the high slip range, it was necessary to smooth the $\tau$ and $\sigma$ recordings by hand. These data represent the stresses measured directly beneath the axle. When the ratio is computed near the midpoint of the wheel-soil interface, the scatter is considerably less. 


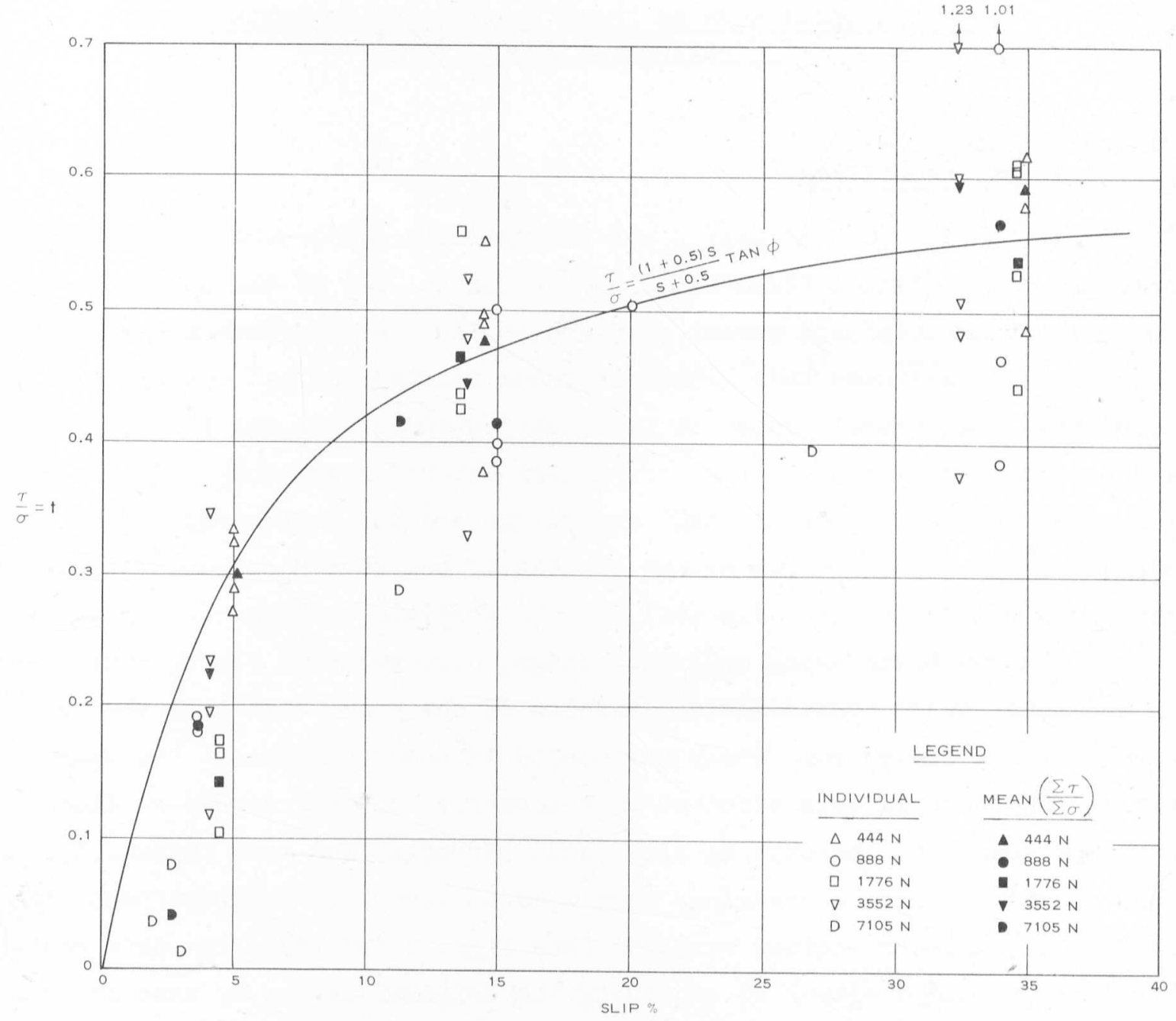

Fig. 6. WES measurements from tests with rigid wheels $\tau / \sigma$ versus slip at $\delta=0 ; G=2.72 \mathrm{~N} / \mathrm{cm}^{3}$ 


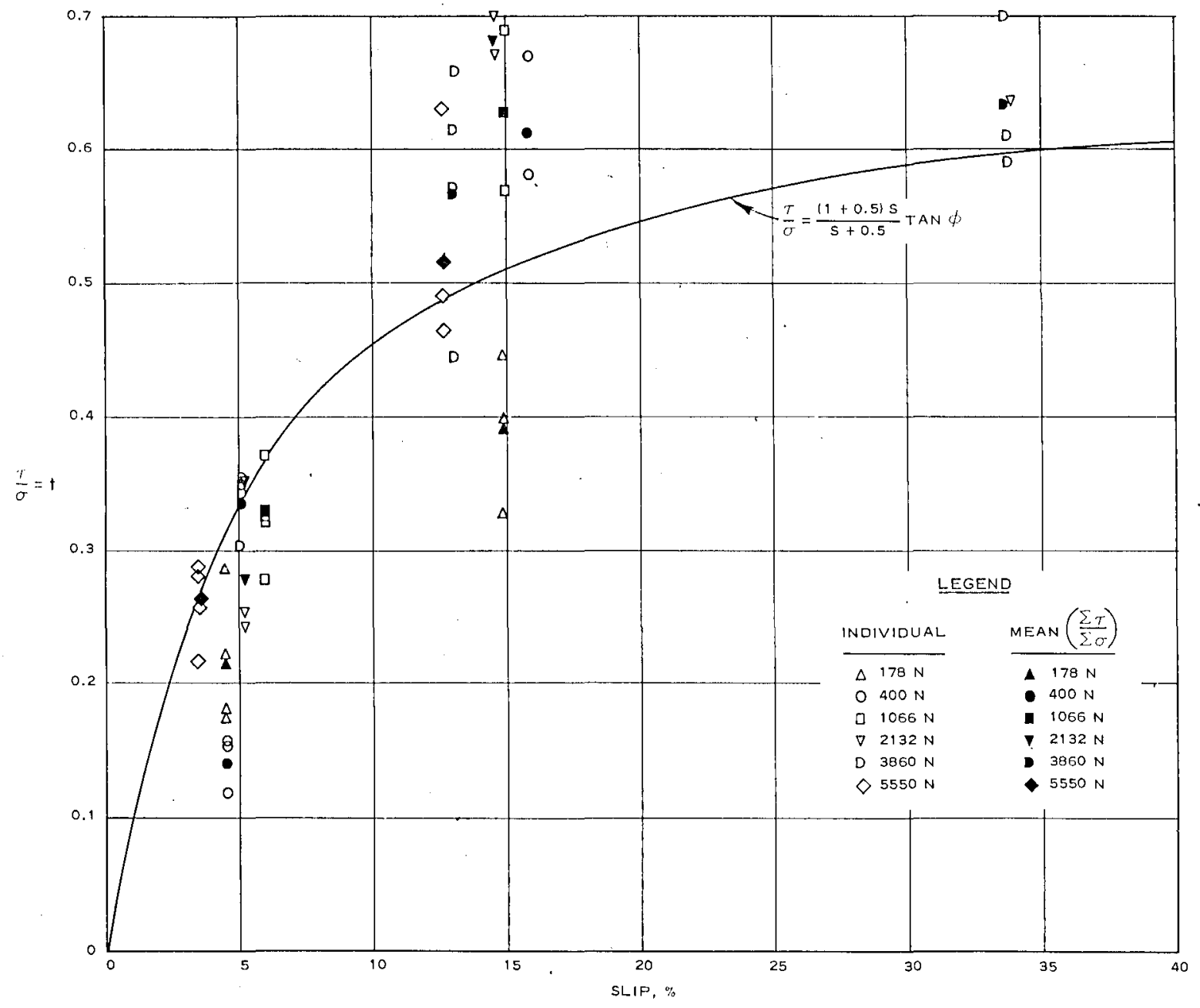

Fig. 7. WES measurements from tests with rigid wheels $\tau / \sigma$ versus slip at $\delta=0 ; G=.5 .44 \mathrm{~N} / \mathrm{cm}^{3}$ 
entails a certain time delay unless highly sophisticated equipment is used. Both methods tend to overlook the fact that these disturbing vibrations are a real phenomenon and not just a nuisance to be eliminated.

33. Also unreliable is the primitive method of using much less sensitive pressure cells to circumvent these problems (apparently the case in Sela's measurements), especially at the extremes of the wheel-soil interface, where "readings of the shear and normal stresses are low and thus a small error in reading causes a large error in the $\tau / \sigma$ value."l7 Because of the shortcomings, pressure cells give only a rough idea of the variations and the order of magnitude of the $\tau / \sigma$ ratios.

Comparison of mean shear/

normal stress ratio to $\mathrm{M} / \mathrm{RW}$

34. This indirect method of checking the theoretical concept is based on the consideration of the mean value of $\tau / \sigma\left(=t_{m}\right)$ taken over the whole contact area, rather than on its variation along the contact length. It can be shown that $t_{m}$ is roughiy equal to the $M / R W$ ratio. Since the $t_{m}$ value can be obtained readily from any $\tau / \sigma$ theory (by graphical construction, if necessary), and $\mathrm{M} / \mathrm{RW}$ can be easily and accurately measured, the relation between the two constitutes a convenient tool of control. 35. The $M / R W$ ratio can be expressed by

$\frac{M}{R W}=\frac{2\left[\int_{-\beta}^{\alpha} \int_{0}^{b / 2} t(\delta, y){ }^{\sigma}(\delta, y) d \delta d y\right]}{2\left[\int_{\beta}^{\alpha} \int_{0}^{b / 2} \sigma_{(\delta, y)} \cos \delta d \delta d y\right]+2\left[\int_{-\beta}^{\alpha} \int_{0}^{b / 2}{ }^{t}(\delta, y){ }^{\sigma}(\delta, y) \sin \delta d \delta d y\right]}$

where

$$
\begin{aligned}
\sigma_{(\delta, y)}= & \text { normal pressure as a function of angle } \delta \text { and the distance } \\
& y \text { from the center of the rigid wheel (fig. 8) } \\
t_{(\delta, y)}= & \text { the corresponding } \tau / \sigma \text { function }
\end{aligned}
$$

In equation 8, the second term of the denominator, which represents the contribution of shear stresses to the load-carrying capacity of the wheel, is a very small quantity compared with the first term, which represents the contribution of normal stresses, $\sigma$. Thus, if the second term is neglected, only a small negative error is generated, and this can be roughly 


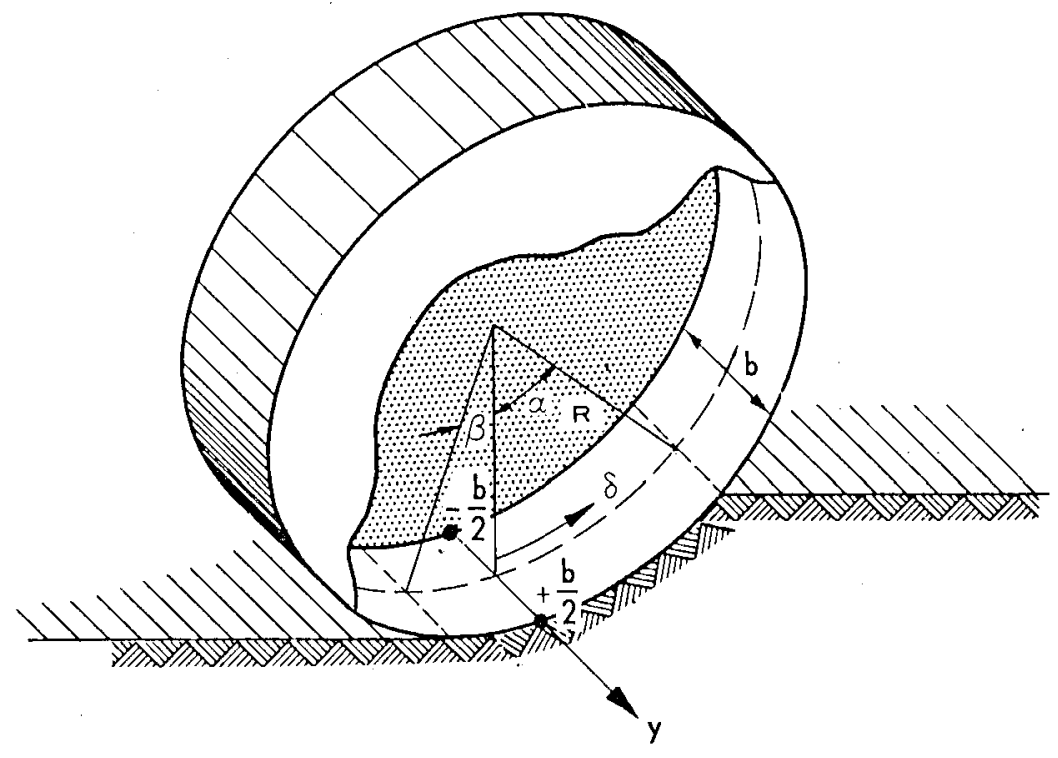

Fig. 8. Rigid wheel coordinates

compensated by simultaneously cancelling the cosine factor in the first term, which slightly increases the value of the denominator.

36. For a qualitative evaluation, equation 8 therefore can be simplified to

$$
\frac{\mathrm{M}}{\mathrm{RW}} \approx \frac{2\left[\int_{\beta}^{\alpha} \int_{0}^{\mathrm{b} / 2} t_{(\delta, y)}{ }^{\sigma}(\delta, y) d \delta d y\right]}{2\left[\int_{-\beta}^{\alpha} \int_{0}^{b / 2} \sigma_{(\delta, y)} d \delta d y\right]}
$$

Equation 9 can be simplified further by replacing the function $t(\delta, y)$ with its mean value $t_{m}$ mathematically defined by

$$
t_{m}=\frac{2\left[\int_{-\beta}^{\alpha} \int_{0}^{b / 2} t_{(\delta, y)} d \delta d y\right]}{b(\alpha+\beta)}
$$

37. Since $t_{m}$ is constant for a given contact zone, it can be put before the integral sign, and the two remaining. integrals in the numerator and denominator cancel. This leads to the simple approximation formula:

$$
\frac{\mathrm{M}}{\mathrm{RW}} \approx t_{\mathrm{m}}
$$


This constitutes a rather crude evaluation, of course, but the general validity of the approximate formula is remarkable since it can be developed without considering wheel width, slip, or soil strength. The deviation from the true $M / R W$ ratio depends only on the $t$ and $\sigma$ functions and on the integration limits of $\alpha$ and $\beta$.

38. To check the degree of approximation, equation 11 was conpared with the exact equation 8 , which had been solved by a computer for all possible combinations of five $t$ distributions and four $\sigma$ functions. Assuming $\beta=0.2 \alpha$, which is close to its experimental value, $M / R W$ was calculated for $\alpha$ values varying from 0.1 to 1.1 radians. Variations in the $\sigma$ and $t$ functions over the width of the wheel can be neglected in these hypothetical computations.

39. The assumed $\sigma$ and $t$ distributions along the contact length are tabulated in fig. 9. Although they are all distorted sine and cosine

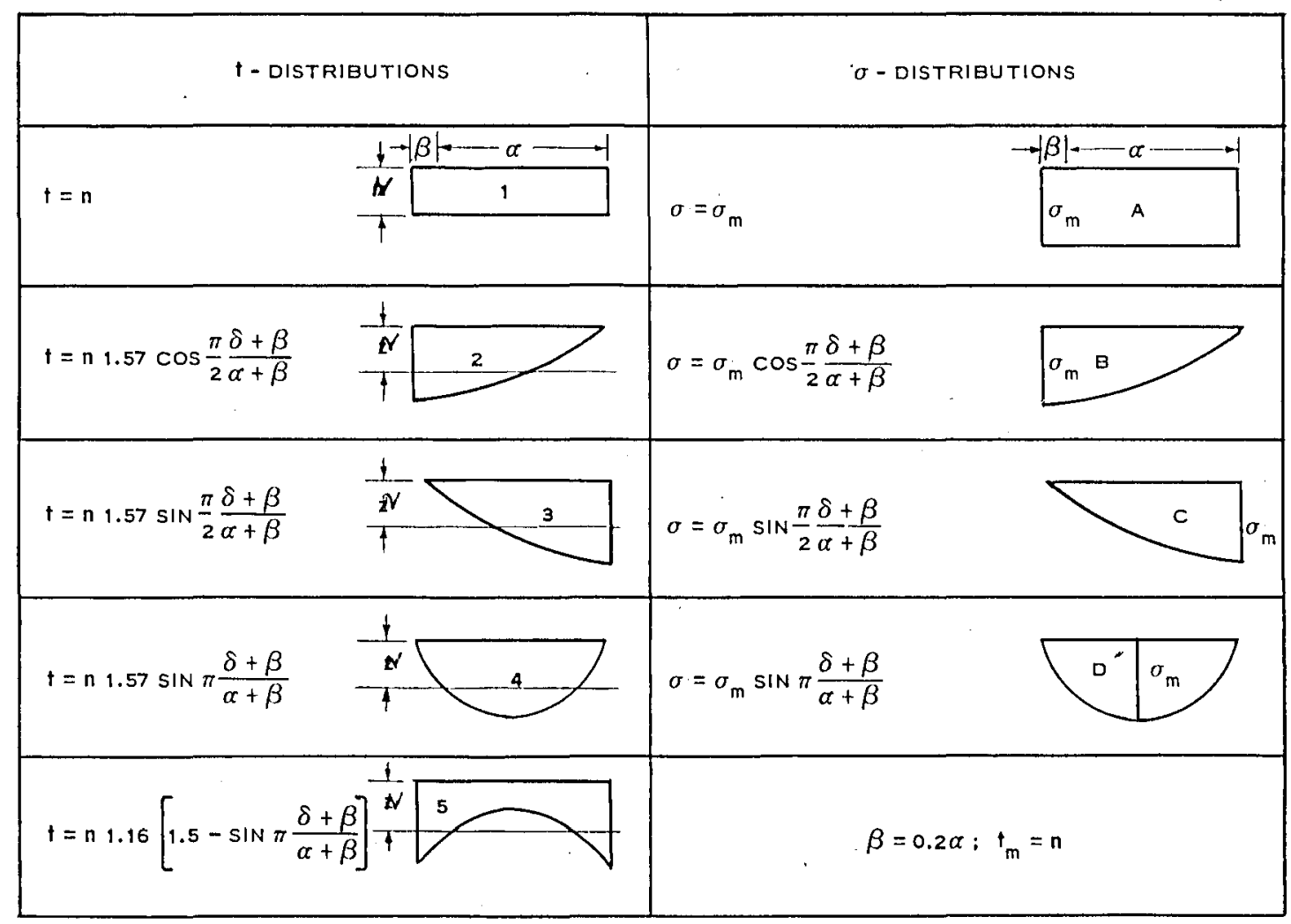

Fig. 9. $\sigma$ and $t$ distributions used for computations functions, the variety of their main features represents, in a qualitative 
manner, all possible types of distributions that can reasonably be assumed for rigid wheels in sand. It is the type of distributions that is important, not how they are mathematically expressed. The $t$ functions have been so formulated that their $t_{m}$ value, as defined by equation 10 , is equal to unity. By multiplying them by a constant $n$, any desired $t_{m}$ value can be introduced $\left(n \cdot I=t_{m}\right)$. The results of these computations are listed in table 1 , and some are graphically illustrated in fig. IO.

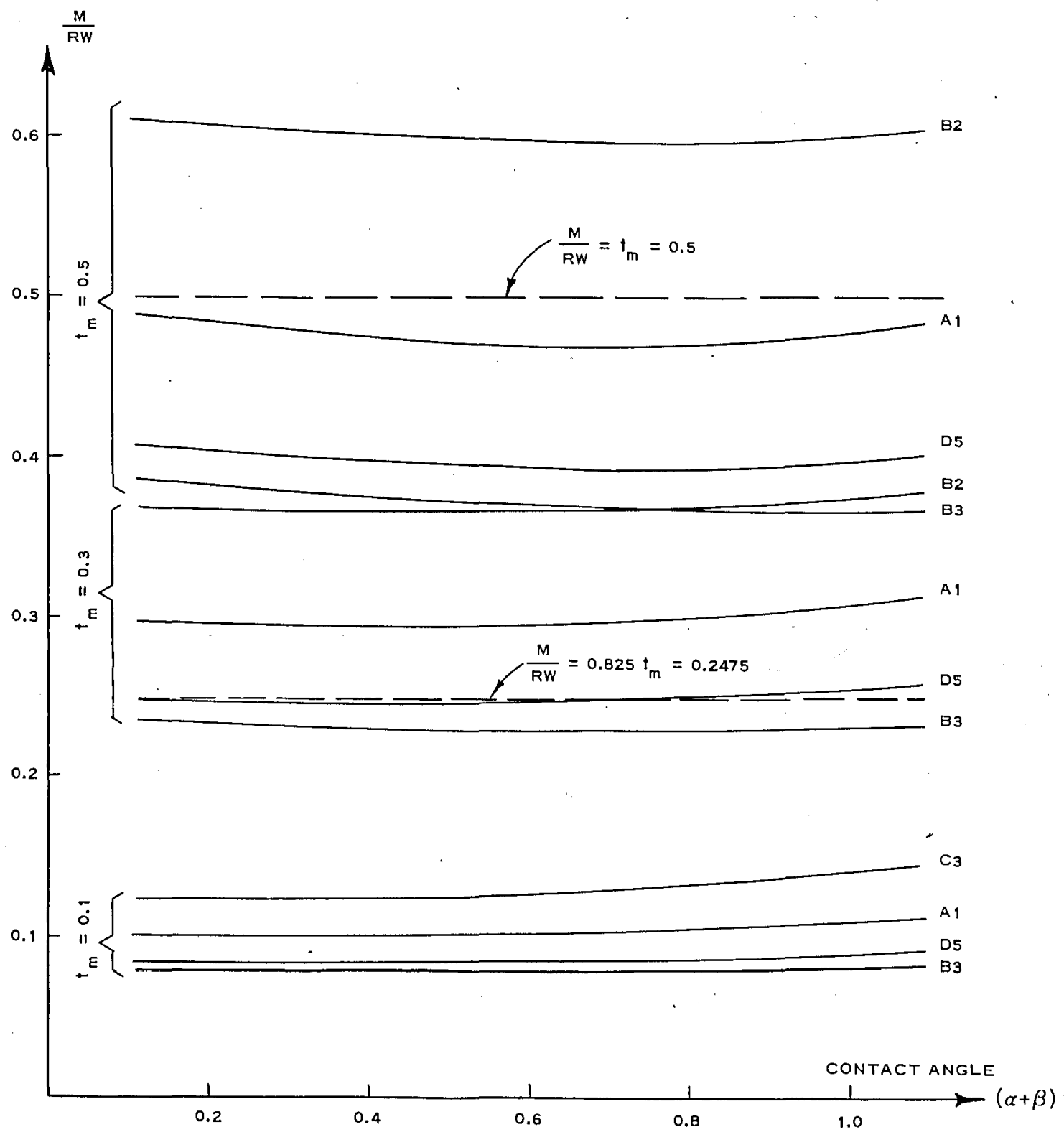

Fig. 10. Results of computations for selected $\sigma$-t combinations 
These were chosen:

a. The $M / R W$ curves with the greatest positive or negative deviation from the $t_{m}$ 'value (combinations B2 or $\mathrm{C} 3$ ' and B3, respectively).

b. The curve for the simplest $\sigma-t$ combination (A.l).

c. The curve for the most probable $\sigma-t$ combination among those investigated (D5).*

40. Of the 360 calculated $\mathrm{M} / \mathrm{RW}$ values (table 1 ), only 10 deviated more than 25 percent frome $t_{m}$ value. These are:

Combination B2

$t_{m}=0.1$

\begin{tabular}{|c|c|c|}
\hline$\alpha$ & $\mathrm{M} / \mathrm{RW}$ & $\begin{array}{c}\text { Deviation } \\
\% \\
\end{array}$ \\
\hline 0.7 & 0.1258 & +25.8 \\
\hline 0.9 & 0.1281 & +28.1 \\
\hline 1.1 & 0.1312 & +31.2 \\
\hline
\end{tabular}

Combination B3

$$
t_{m}=0.5
$$

\begin{tabular}{|c|c|c|}
\hline$\alpha$ & $\mathrm{M} / \mathrm{RW}$ & $\begin{array}{c}\text { Deviation } \\
\%\end{array}$ \\
\hline 0.5 & 0.3702 & -26.0 \\
\hline 0.7 & 0.3657 & -26.9 \\
\hline 0.9 & 0.3634 & -27.3 \\
\hline 1.1 & 0.3634 & -27.3 \\
\hline
\end{tabular}

Combination $\mathrm{C} 3$

$$
t_{m}=0.1 \text {. }
$$

$\frac{\alpha}{0.7} \frac{\mathrm{M} / \mathrm{RW}}{0.1288} \frac{\begin{array}{c}\text { Deviation } \\ +28.8\end{array}}{0.9}$

$0.90 .1354+35.4$

$1.10 .1451+45.1$

However, none of these are probable combinations. C3 is the most improbable of all those investigated, $* *$ and the extreme positive deviations occur only for high contact angles $(\alpha>0.7)$ at a very low $t_{m}$ value. But Sela's theory, as well as the new concept that will be presented (Part V), indicates that for high contact angles the $t_{m}$ value is greater than 0.1 , so incidental extreme positive deviations can be disregarded. The highest negative deviations (B3) are barely above 25 percent and can also be disregarded. Equation 11 can then be written:

$$
\frac{M}{R W}=t_{m} \pm 25 \%
$$

As mentioned previously, equation Ila is an easy-to-handle tool" of control. If the experimental $M / R W$ values do not match the theoretical $t_{m}$ values within a 25 percent error margin, the basic theory may be considered erroneous.

* The $t$ function (5) comes nearest to the distribution found by Sela. All measurements of $\sigma$ distributions under rigid wheels on sand indicate a type of distribution comparable to D (fig. 9).

** The most probable combination, D5, presents only negative deviations, with the extreme value of -21.6 percent. 
41. If it is assumed that, during a particular test series, the typical features of the $t$ function and the $\sigma$ distribution do not change, equation 11 can be rewritten:

$$
\frac{\mathrm{M}}{\mathrm{RW}} \approx \mathrm{A}_{\text {ot }} \mathrm{t}_{\mathrm{m}}
$$

The subscripts $\sigma$ and $t$ indicate that the coefficient $A$ is valid only for one particular o-t combination, not for the whole group of possible combinations, and is intended to approximate only one individual curve. For example, the coefficient $A_{D 5}=0.825$ approximates the D5 combination $\pm 5 \%$ (fig. .9 ) if, as before, the extreme deviations at $\alpha=0.9(+7 \%$ ) and $\alpha=1.1(+11.5 \%)$ for $t_{m}=0.1$ are disregarded. Since a greater deviation may occur in the actual o-t combination, it seems fair to write:

$$
\frac{\mathrm{M}}{\mathrm{RW}}=\mathrm{A}_{\sigma \mathrm{t}} \mathrm{t}_{\mathrm{m}} \pm 10 \%
$$

42. The effective Aot value is unknown for any real problem, so equation $12 a$ can only be used to compare the variations of $M / R W$ and $t_{m}$, not their absolute values. Because the 10 percent error margin is small, equation $12 a$ can be stated:

$$
\frac{\mathrm{M}}{\mathrm{RW}} \sim \mathrm{t}_{\mathrm{m}}
$$

This means that $M / R W$ varies directly as $t_{m}$, if it can be assumed reasonably that the general features of the $\sigma$ and $t$ distributions do not change radically during the test program. 


\section{PART III: TEST RESULTS USED TO EVALUATE THEORIES}

43. A series of constant-slip tests, in which the contact length was varied by increasing the load, provided the conditions necessary (i.e. $\sigma-t$ combination is basically invariable with contact length) for equation $12 \mathrm{~b}$ to be applied. These tests were run in an air-dry sand, classified SP under the Unified Soil Classification System. Sand at two strength levels was used, and the penetration resistance gradients were approximately 2.72 and $5.44 \mathrm{~N} / \mathrm{cm}^{3}$ (0-6 in. cone indexes of 30 and 60 , respectively). The equipment ard test techniques used have been described by McRae, Powell, and Wismer. 18

44. The normal or radial stresses were measured with deflecting diaphragm-type transducers mounted so that the active portion of each cell was flush with the surface of the center line of the wheel. Tangential stresses were measured with a cantilever beam-type transducer. One end of the beam was flush with the outer surface of the wheel; the other securely anchored within the wheel.

45. The contact length was of particular importance in this study. The classical measure of sinkage was not adequate for determining contact length, since it does not account for the bow wave before and the upheaval behind the wheel. Pressure cells were considered inadequate to determine the contact length, because of the difficulties discussed in paragraphs 32 and 33. Therefore, a mechanical switch was placed at the wheel surface, and the time-in-soil recorded on a direct-writing oscillograph. However, a force of approximately $3.5 \mathrm{~N}$ was needed to activate the switch, so the recorded contact length was somewhat smaller than the actual one, but since it did not affect the qualitative interpretation of the test results (see footnote on page 32), no effort was made to correct the systematic error.

46. $\mathrm{M} / \mathrm{RW}$ curves as functions of contact length are plotted for four test series in figs. 11-14. Since slip, soil strength, and load were not the same as the preestablished values in all cases, the data had to be corrected before the curves could be drawn. The actual measured values are 
shown by marked points; the areas which would contain the corrected readings are circumscribed by rectangles.

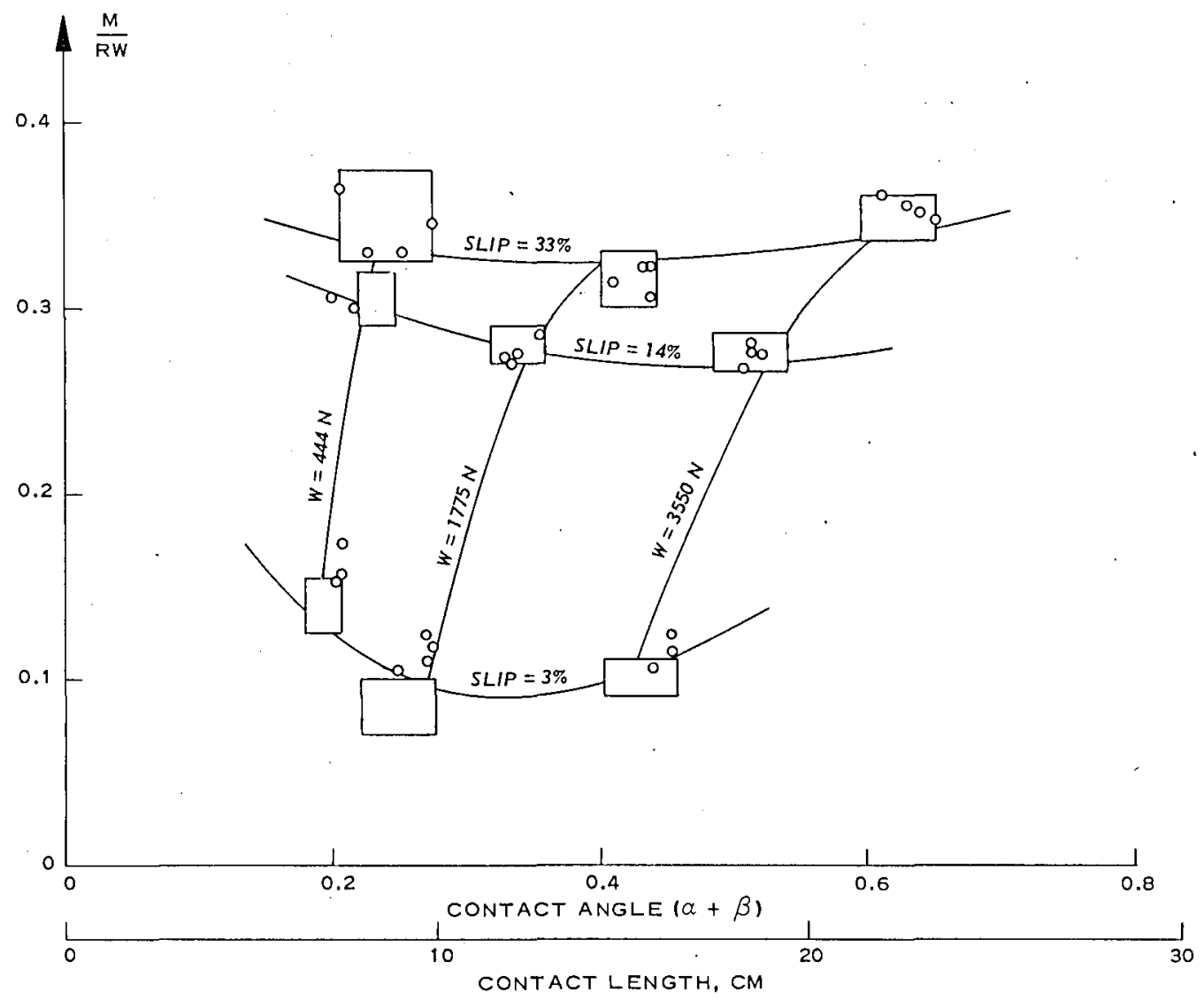

Fig. 11. Measured $\mathrm{M} / \mathrm{RW}$ versus contact length Mortar sand

$$
\begin{array}{rlrl}
\mathrm{G} & =5.44 \mathrm{~N} / \mathrm{cm}^{3} & \tan \varnothing & =0.65 \\
\mathrm{R} & =35.5 \mathrm{~cm} & \mathrm{~b} & =30.5 \mathrm{~cm}
\end{array}
$$




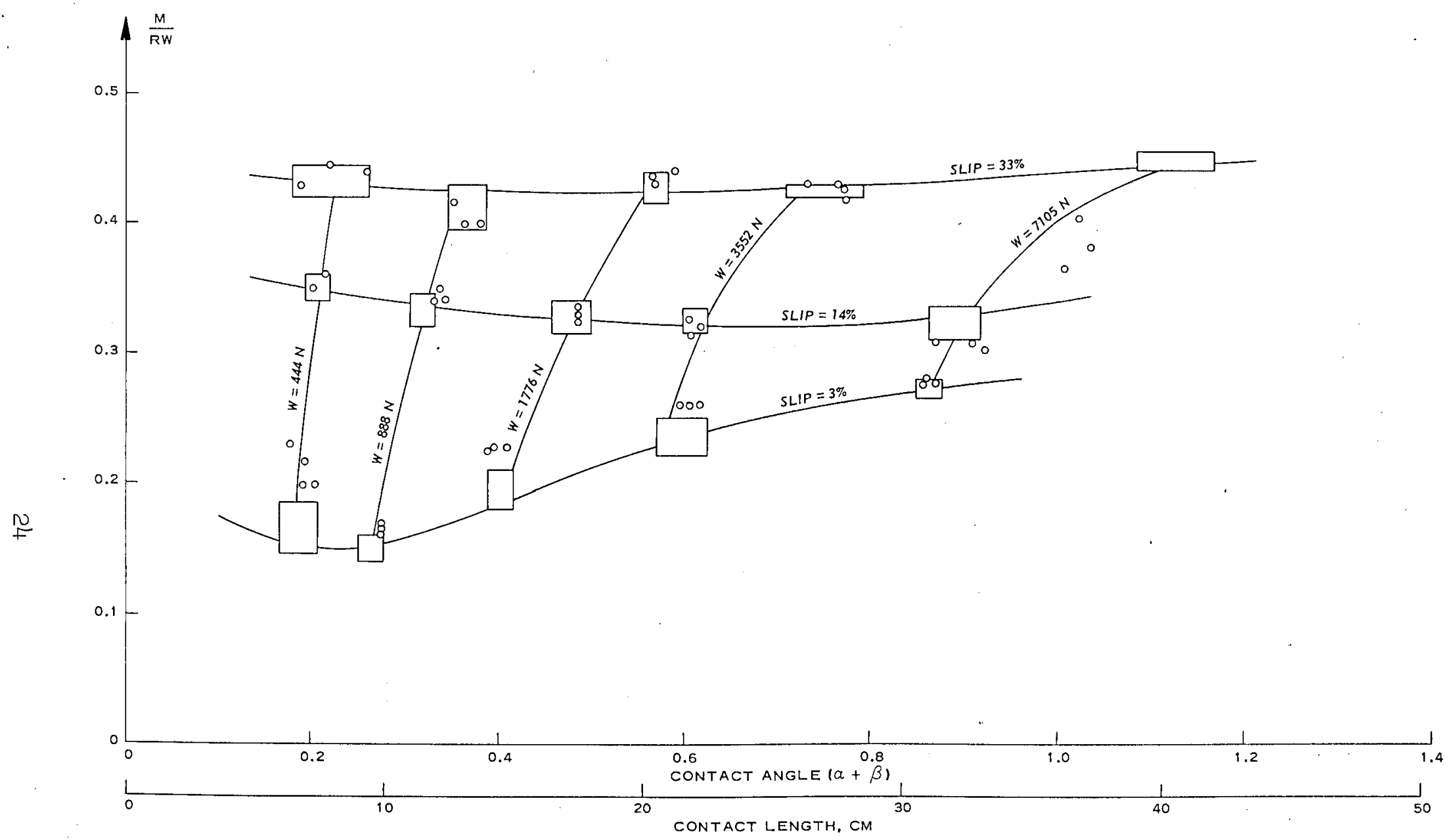

Fig. 12. Measured $\mathrm{M} / \mathrm{RW}$ versus contact length Mortar sand

$$
\begin{array}{rlrl}
\mathrm{G} & =2.72 \mathrm{~N} / \mathrm{cm}^{3} & \tan \phi & =0.60 \\
\mathrm{R} & =35.5 \mathrm{~cm} & \mathrm{~b} & =30.5 \mathrm{~cm}
\end{array}
$$




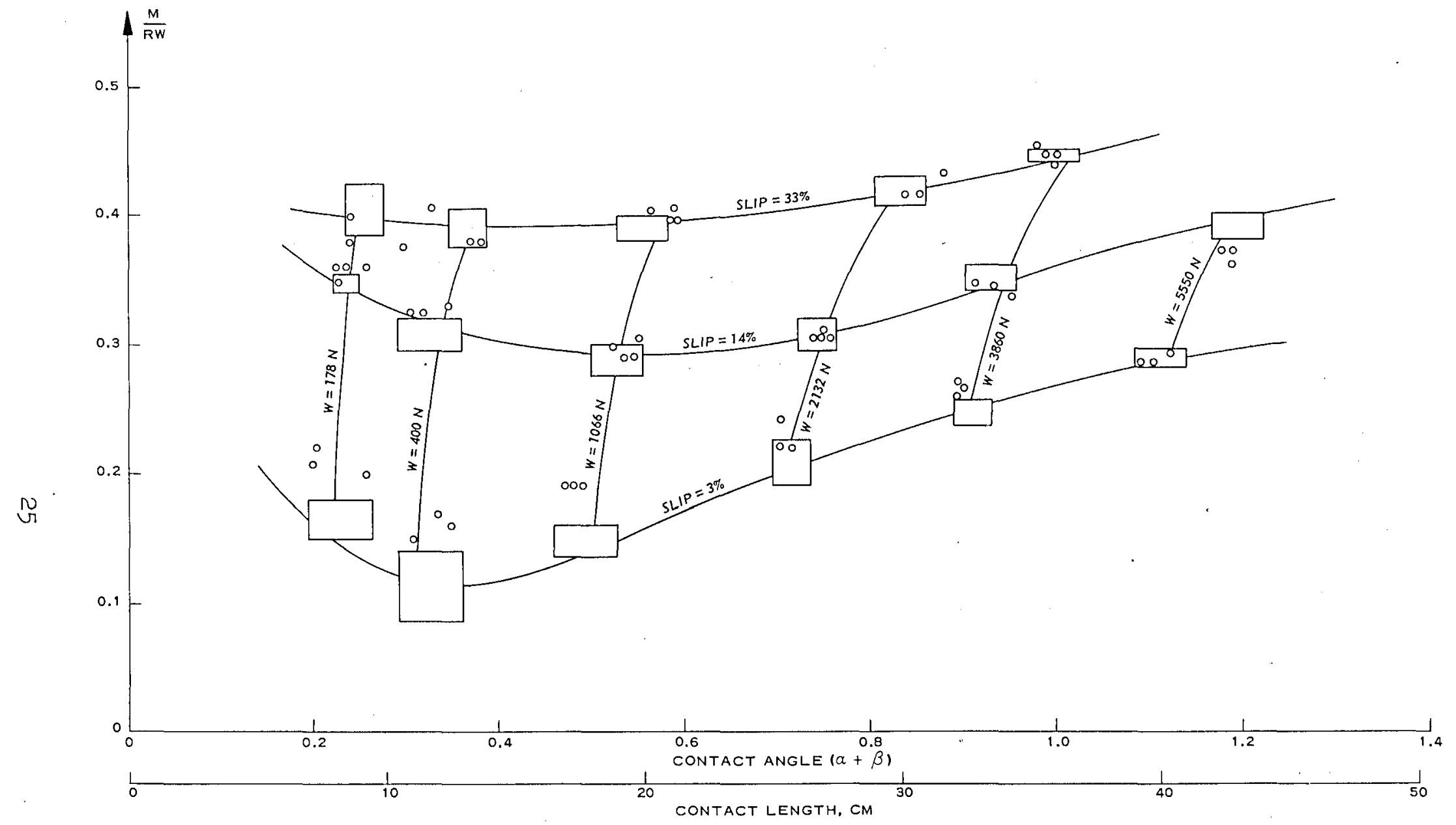

$\sum_{n}^{\infty}$

Fig. 13. Measured $M / R W$ versus contact length Mortar sand
$\mathrm{G}=5.44 \mathrm{~N} / \mathrm{cm}^{3}$
$\tan \varnothing=0.65$
$\mathrm{R}=35.5 \mathrm{~cm}$
$\mathrm{b}=7.6 \mathrm{~cm}$ 


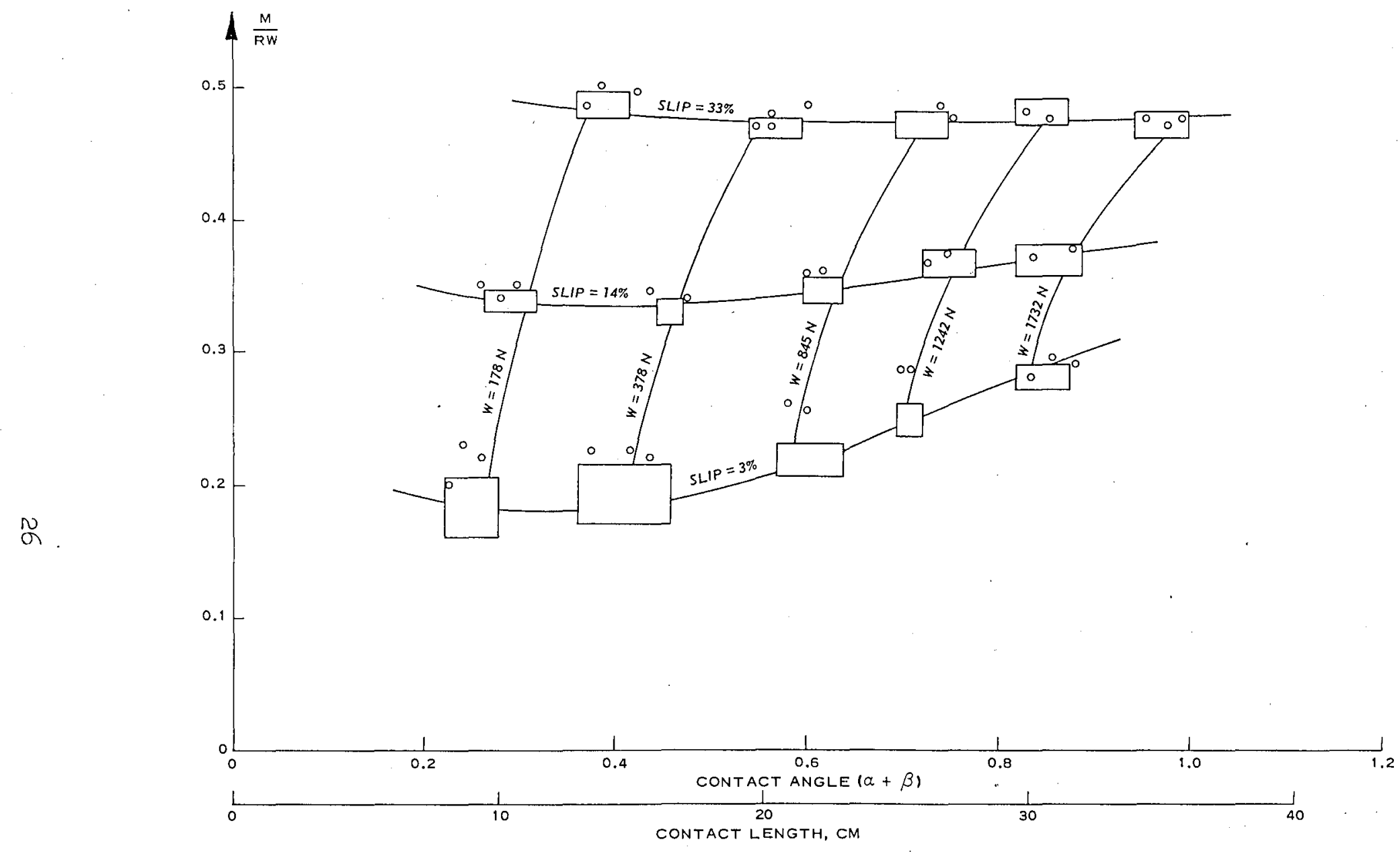

Fig. 14. Measured $\mathrm{M} / \mathrm{RW}$ versus contact length

Mortar sand

$$
\begin{array}{rlrl}
G & =2.72 \mathrm{~N} / \mathrm{cm}^{3} & \tan \varnothing & =0.60 \\
R & =35.5 \mathrm{~cm} & \mathrm{~b} & =7.6 \mathrm{~cm}
\end{array}
$$


47. Two criteria have been developed for comparing $\mathrm{M} / \mathrm{RW}$ curves to the theoretical $t_{m}$ curves. The first, equation lla, states that for the same contact length, the absolute $M / R W$ values should coincide with the absolute $t_{m}$ values within a 25 percent error margin. In the second method of checking, using equation 12b, certain qualitative descriptive terms should apply to both the experimental $\mathrm{M} / \mathrm{RW}$ curves and the theoretical $t_{\mathrm{m}}$ curves.

48. The main qualitative features of the $M / R W$ curves in figs. $11-14$ are:

a. The higher the slip, the higher the $M / R W$ ratio.

b. The first portion of each $\mathrm{N} / \mathrm{RW}$ curve is concave upward.

c. The length of the concave upward portion of the $M / R W$ curves seems* to increase as the slip increases.

d. The curvature in the concave upward. portions of the $M / R W$ curves is more pronounced at lower slip values.

e. The data strongly indicate that for zero contact length, the $M / R W$ ratio is not zero, but a definite, positive value.

\section{Determination of the $t_{m}$ Values Using Sela's Theory}

49. To check sela's theory against the test results, the theoretical $t_{m}$ values of this theory must be determined. Nine different t-distributions were obtained by applying Sela's theoretical concept to the WES test data. These are given in fig. 15 and are based on the following data:

$$
\begin{aligned}
& \mathrm{R}=71 / 2=35.5 \mathrm{~cm} \\
& \mathrm{k}=2.54 \mathrm{~cm}(1 \mathrm{in} .) \\
& \mathrm{m}=0.5 \\
& \tan \varnothing=0.5 \\
& \operatorname{siip}=3 \%, 14 \%, \text { and } 33 \%
\end{aligned}
$$

* Some curves were too short or too flat to recognize the end of the concave upward portion. 

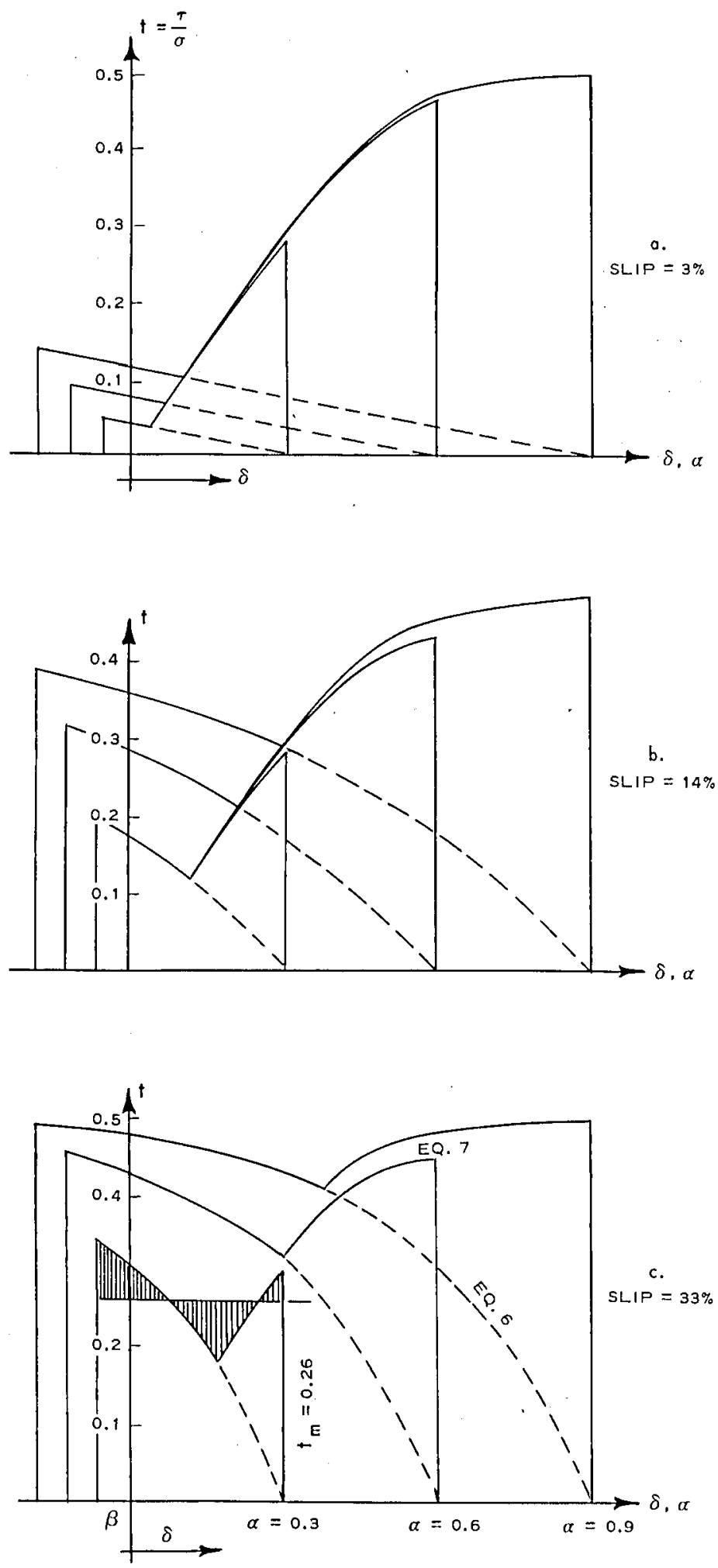

Fig. 15. $\tau / \sigma$ variation along the contact length according to Sela's theory $\tan \phi=0.5 ; \mathrm{R}=35.5 \mathrm{~cm} ; \mathrm{b}=0.2 \alpha$ 
$k$ and $m$ are not measured for this sand, since their exact determination is highly subjective. 5 The values used by selal7 were $\mathrm{k}=2.54 \mathrm{~cm}$, and $m=0.65$, but he pointed out that the value of $m$ was too high; therefore, a slightly smaller value $(0.5)$ was used in this analysis. Tan $\varnothing=$ 0.5 was chosen as a convenient reference value. The actual friction coefficients of the test sand were 0.6 and 0.65 , respectively, so the ' $t$ and $t_{m}$ values (figs. 15 and 16, respectively) were multiplied by a factor

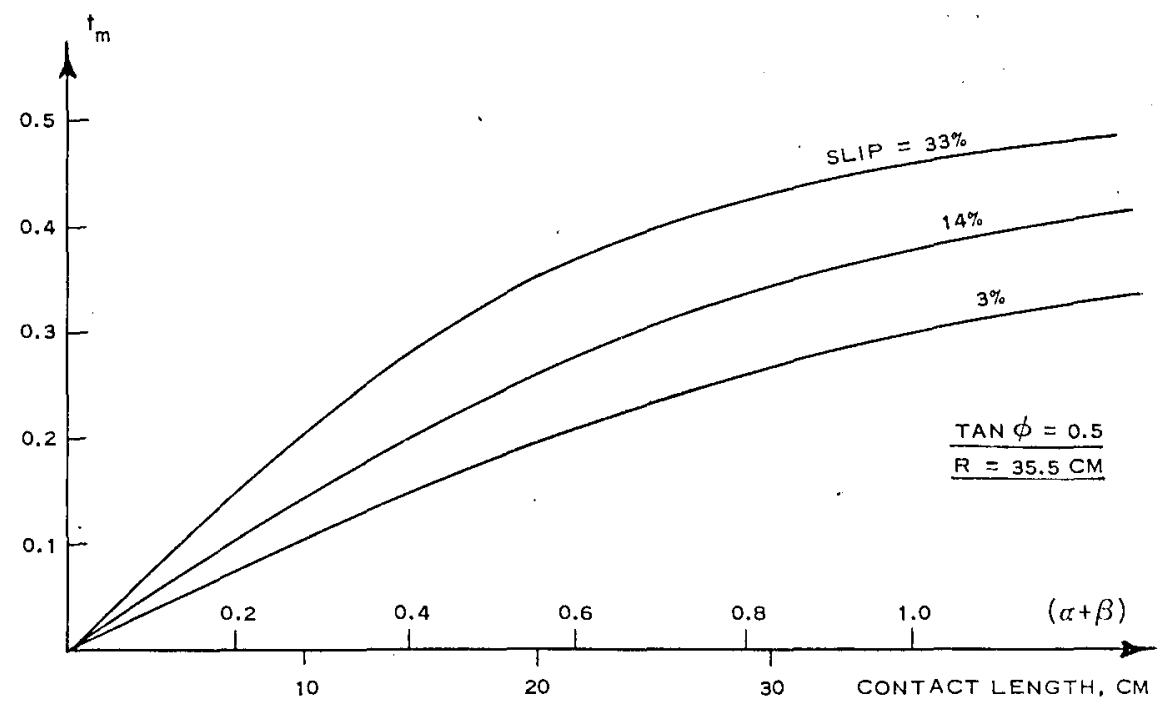

Fig. 16. Variation of $t_{m}$ with contact length, using Sela's theory

of 1.2 and 1.3 , respectively. The pertinent $t_{m}$ values were obtained from individual t-distribution curves by graphical construction (fig. 15q) and are plotted as functions of contact length in fig. 16 .

Theoretical and Experimental Results Compared Using Sela's Theory

Comparison of absolute values

50. The corrected $t_{m}$ curves of fig. 16 and the \pm 25 percent error limits were superimposed onto the corresponding $\mathrm{M} / \mathrm{RW}$ curves in figs. 17 and 18. To avoid obscuring the graphical representation, the $\mathrm{M} / \mathrm{RW}$ curves were regrouped in these figures. For Sela's theory to be correct, all 

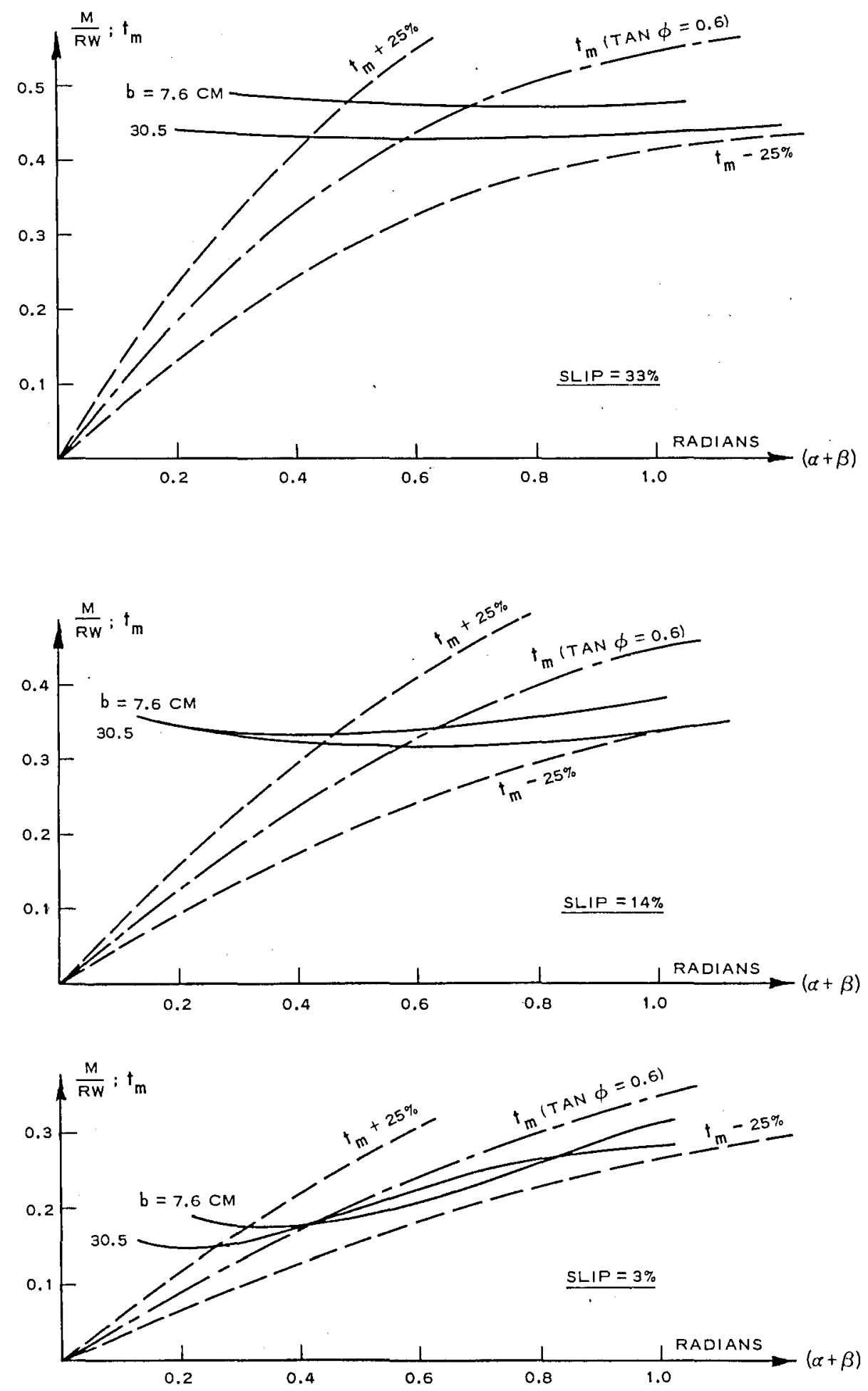

Fig. 17. Superposition of experimental values onto theoretical

$t_{m}$ values drawn from Sela's theory; $G=2.72 \mathrm{~N} / \mathrm{cm}^{3}$ 

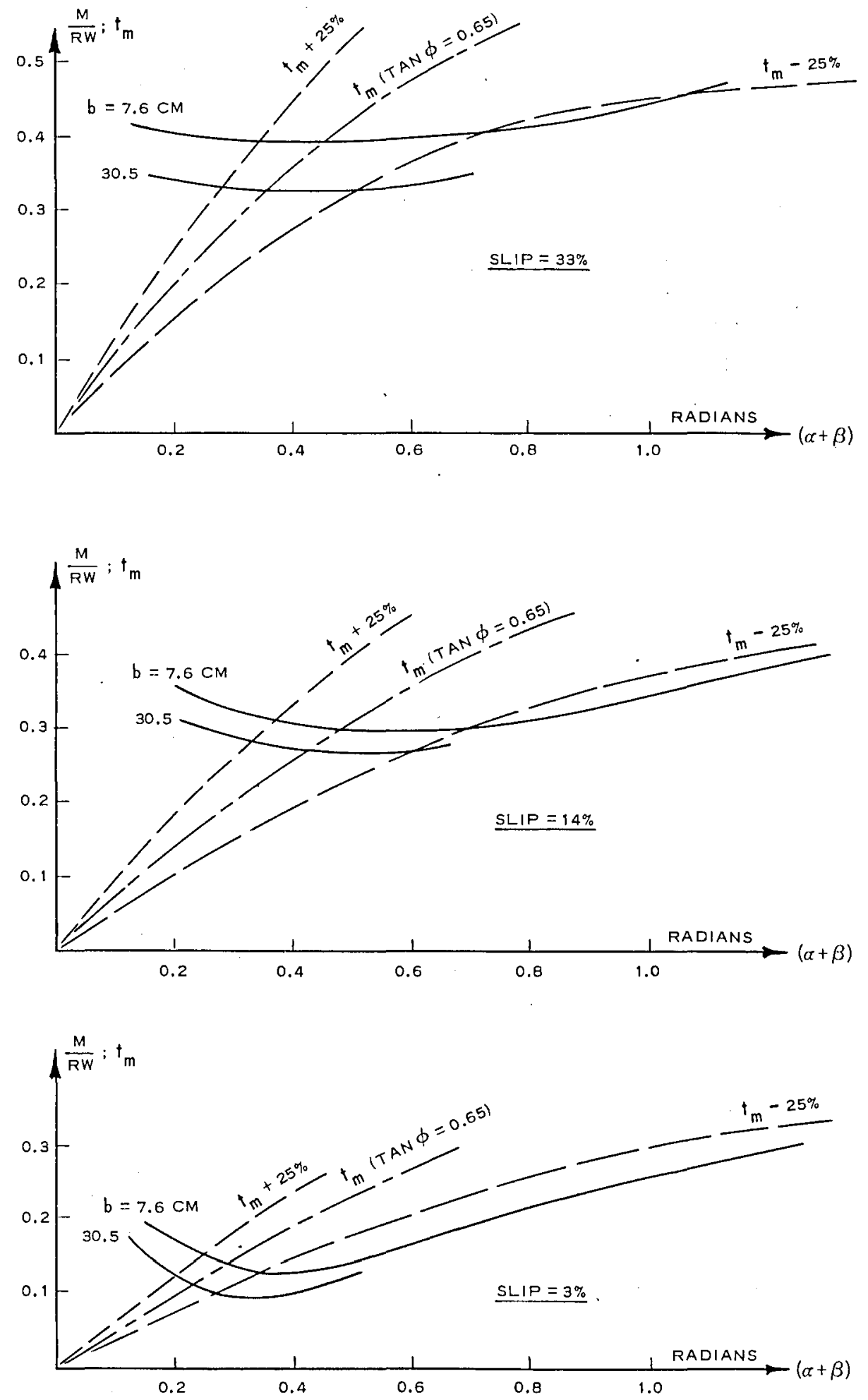

Fig. 18. Superposition of experimental values onto theoretical $t_{m}$ values drawn from Sela's theory; $G=5.44 \mathrm{~N} / \mathrm{cm}^{3}$ 
experimental $\mathrm{M} / \mathrm{RW}$ curves should certainly fall within the +25 percent Iimits; however, to a significant degree, they do not.*

Comparison of variations

51. The second check of the theory, provided by equation 12b, states that $M / R W$ varies with contact length in the same manner as $t_{m}$, if the o-t combination is assumed to be basically invariable with contact length. This assumption is essentially valid for constant-slip tests; therefore, the $t_{m}$ curves of $f i g .16$ should match, point by point, the main qualitative features of the $M / R W$ curves (paragraph 48 ) if sela's theory is correct. For the five enumerated points, only point a is in agreement. Sela's theory, therefore, must also be rejected on the basis of the second criterion.

\section{Discussion of Results Obtained by Sela}

52. In Sela's investigation, the measured $\cdot \tau / \sigma$ distribution agreed closely with his theoretical predictions. This can be explained by comparing the results of tests on the weaker sand ( $\tan \phi=0.6$, fig. I7) with those on stronger sand ( $\tan \phi=0.65$, fig. 18). For high contact angles $(\alpha+\beta>0.5$ radians $)$, the $M / R W$ curves for the weak sand are a.l. within the limits of Sela's theory; for the dense sand, they are not. Since the sand used by Sela was even weaker ( $\tan \phi=0.44$, bevameter reading), and the contact angles $(\alpha+\beta)$ ranged from 0.6 to 1.2 radians, it is not surprising that the measured $\tau / \sigma$ variations matched his theory fairly well. The lack of agreement appears only when a broader spectrum of contact angles and soil strengths is considered.

\section{Validity of Any shear Stress Relation}

53. The second method of checking disqualifies all theories on the

* This percentage would not change significantly if the error due to the faulty measurement of contact length were eliminated. The displacement to the right of the experimental $M / R W$ curves would diminish the portion to the left of the curves and increase it on the right. 
shear-to-normal stress ratio of wheels developed from the shear stressdisplacement relation (equation 2). The very mathematical nature of this exponential function will not permit conditions $\underline{b}$ and $\underline{e}$ (paragraph 48 ) to be fulfilled by such a concept. When equation 2 is used as a basic relation to predict the $\tau / \sigma$ ratio for wheels, the resulting $t_{m}$ curves as functions of contact length will always be concave downward and will always pass through the zero point for zero contact length, unless the equation is distorted by additional terms in such a manner that its exponential nature can no longer be recognized. 


\section{Development of Concept}

54. It has been shown that the soil rupture patterns beneath moving wheels and those obtained by simple shear test devices are not the same. Therefore, any approach to soil-wheel mechanics must be based entirely upon consideration of an actual wheel and the corresponding pattern of soil flow. The rough general features of the soil deformation pattern beneath moving rigid wheels have been established through research based on visual observation of soil-wheel interaction conducted at Grenoble 13 and Newcastle upon Tyne. 14 From these studies, two principal regions within the wheel-soil interface have been distinguished: a rearward region in contact with the soil in the elastic state (Iunuze), * and a forward region in contact with the soil in a perfect plastic state of actual flow.

55. These studies, however, were limited. No quantitative data are available that reflect changes in the lunule due to slip, wheel geometry, or soil properties. The shapes of the three-dimensional lunule and forward soil body are unknown. Accordingly, the principal assumptions concern the boundaries of three different zones within the wheel-soil interface: the lunule zone, the bulldozing zone, and the lateral flow zone.

56. In the three-dimensional case, it is indeed logical to subdivide the main forward region into two zones of different soil behavior. The principal assumption is that a state of actual soil flow is maintained for the total forward region, but the two zones differ in the direction

* This point of view is not textually supported by Wong and Reece.14 While Boucherie13 refers to the moon-shaped soil mass as being rigidly attached to the wheel and moving around the instantaneous center of rotation, Wong and Reecel4 consider it as being in an active (plastic) state bounded by a logarithmic spiral. Besides the misleading term "active state" (an active state is defined as being a state of plastic failure in which the weight of the considered soil mass supports the failure process, which is not the case here), another controversial point has to be mentioned. Wong and Reece noted indeed that the soil "moves backward by means of rotation approximately about the instantaneous center of movement," a statement which is somewhat in contradiction to the hypothesis of a logarithmic spiral boundary. 
of the soil flow. In the bulldozing zone, the soil particles are assumed to move forward in the vertical plane of travel; in the lateral flow zone, the soil is assumed to escape from under the wheel by moving parallel to the vertical plane through the wheel axle. The division into zones of the wheel-soil interface is shown in fig. 19.

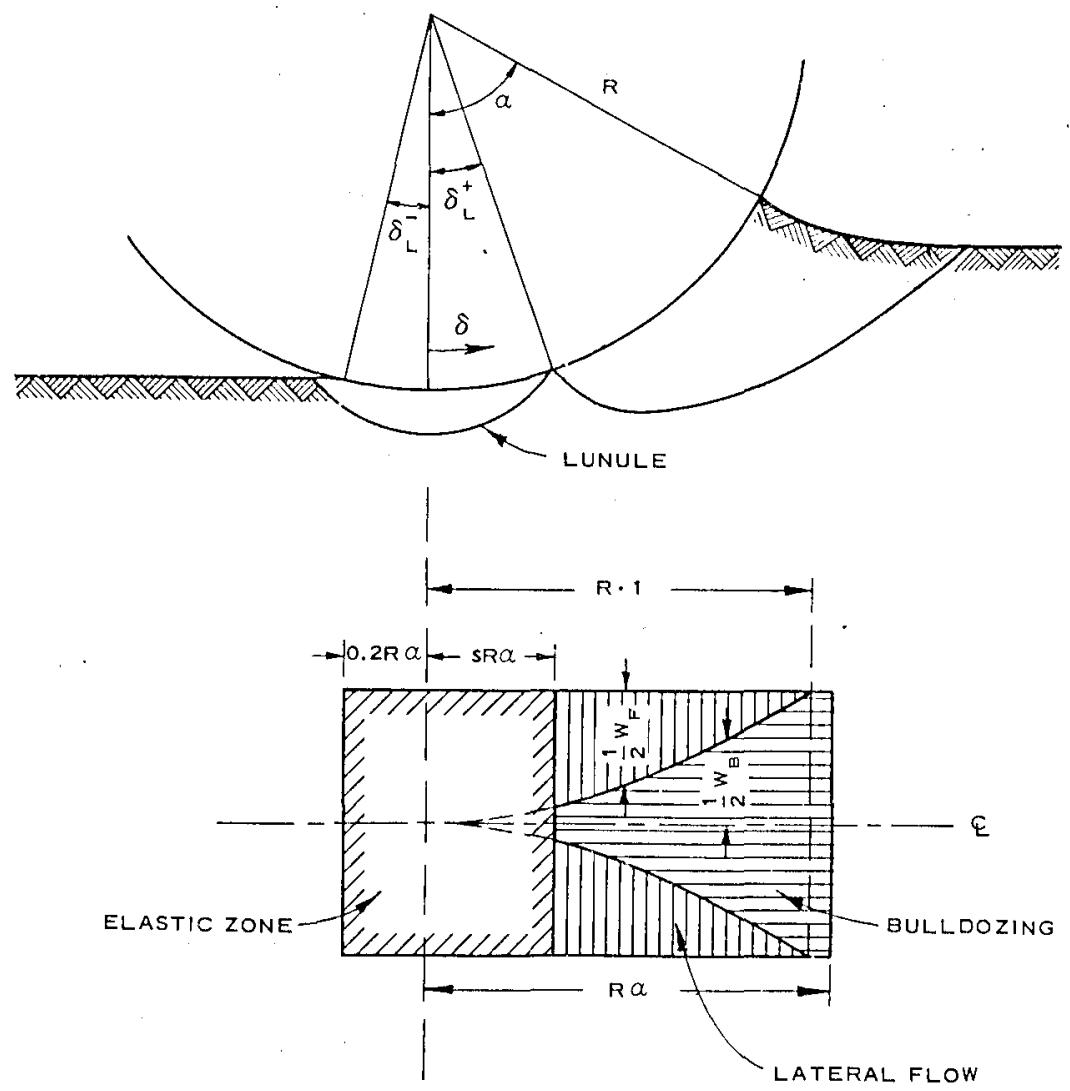

b.

Fig. 19. Zoning of the wheel-soil interface

\section{Iunule zone}

57. The width of the Iunule zone is assumed to be equal to the width of the wheel:

$$
\mathrm{w}_{\mathrm{L}}=\mathrm{b}
$$

The relative length of the lunule zone, with respect to the total contact length, is primarily a function of slip. 14 At very low positive slips, the 
lunule is barely distinguishable; 13 at 100 percent slip, it covers the whole contact length. 14 It is assumed that the relation between the length of the lunule zone and slip is linear. The portion of the lunule zone forward of the vertical reference position $(\delta=0)$ is then (fig. 19).

$$
\mathrm{RS}_{\mathrm{L}}^{+}=\mathrm{sR} \alpha
$$

If it is assumed that $\beta=0.2 \alpha$, the rearward portion of the lunule zone has to be limited for $s>0.2$, which is approximately the maximum observed in testing. Hence

$$
\mathrm{RS}_{\mathrm{I}}^{-}=0.2 \mathrm{R} \alpha \quad(\mathrm{s}>0.2)
$$

For slip values less than 0.2 , it is assumed that $R_{\mathrm{I}}^{-}=\mathrm{RS}_{\mathrm{L}}^{+}$. The total length of the lunule zone is then

$$
\begin{array}{cc}
\ell_{L}=R\left(\delta_{I}^{+}+\delta_{I}^{-}\right)=2 s R \alpha & (s<0.2) \\
\ell_{I}=(0.2+s) R \alpha & (s>0.2)
\end{array}
$$

58. The $\tau / \sigma$ ratio ( $t$ ) for that section of the wheel-soil, interface within the Iunule is less than $\tan \phi^{*}$ because the lunule is in a nonplastic state. It was found to be very difficult to make any assumptions about the t-variation within this zone, even though the $t$ value along the outer limit of the lunule, which is a rupture surface, is known $(t=\tan \phi)$. Therefore, the $t$ value was measured at the center line of the wheel by means of normal and tangential pressure transducers incorporated at the rolling surface. The readings for $\delta=0$ are given in figs. 6 and 7; the large scatter inherent in such measures is apparent. At high slip values, only those $t$ values that could be read clearly on the recordings are listed. Nevertheless, a general trend of the $t_{(\delta=0)}$ values as a function of slip can be recognized that can be expressed as the hyperbolic function

* Because of the sand-glued wheel surface, the maximum wheel-soil friction is assumed to be equal to the internal soil friction. 


$$
t_{(\delta=0)}=\frac{(1+m) s}{s+m} \tan \phi
$$

The value of the constant that fits best in both cases is $m=0.05$. Thus,

$$
\begin{aligned}
& s=3 \% ; t_{(\delta=0)}=0.394 \tan \varnothing \\
& s=14 \% ; t_{(\delta=0)}=0.774 \tan \varnothing \\
& s=33 \% ; t_{(\delta=0)}=0.913 \tan \varnothing
\end{aligned}
$$

These numerical values, although determined for a particular point, were considered representative of the total zone of the lunule

$$
t_{(\delta=0)}=t_{I}
$$

\section{Bulldozing zone}

59. In the bulldozing zone, all soil movements occur in the planes of wheel rotation; there is no lateral flow. As pointed out earlier, the soil in the immediate neighborhood of the wheel within the bulldozing zone is in a perfect plastic condition. The rolling surface of the wheel is assumed to be a rupture surface, and the $t$ value, therefore, is

$$
t_{B}=\tan \varnothing
$$

It is known that along the center line of the contact area, the bulldozing zone extends from the leading edge back to the edge of the lunule. 14 It is obvious, however, that the bulldozing cannot cover the entire width of the wheel everywhere. Based on the assumptions already made, this would lead to extremely high-overall $t_{m}$ values, for both low and high slips.*

* If it were assumed that the bulldozing zone covered the whole width of the wheel, it would largely predominate over the lunule zone at low slip values. Since $t=\tan \varnothing$ is assumed for the bulldozing zone, the $t_{m}$ value of the total wheel-soil interface would be close to tan $\varnothing$. At high slips, the lunule zone dominates. Since at high slips the $t$ value of the lunule zone is near the maximum $\tan \phi$, the overall $t_{m}$ value is close to the maximum. 
60. Therefore, an assumption concerning the lateral limits of the bulldozing zone was necessary. It is felt that the increase of the bulldozing effect with the contact angle is faster than a linear rate. Hence, the width of the bulldozing zone, $w_{B}$, is assumed to increase with the positional angle by a parabolic, rather than a linear, function. The simplest expression of this kind is obtained by setting $\mathrm{w}_{\mathrm{B}}=0$ for. $\delta=0$, and $\mathrm{w}_{\mathrm{B}}=\mathrm{b}$ for $\delta=1$ (radian). A funnel-shaped bulldozing zone results (fig. 19b), the equation for which is

$$
\mathrm{w}_{\mathrm{B}}=\mathrm{b} \delta^{2} \cdot(\delta \text { in radians })
$$

Equation 18 was chosen for its mathematical simplicity, but it also has physical meaning, since $\delta=I$ radian $(\approx 57 \mathrm{deg})$ is roughly the maximum contact angle that can be obtained under reasonable operating conditions. Equation 18 states that, even at the leading edge of the wheel, the bulldozing zone does not cover the full width, $b$, of the wheel when $\alpha<1$ radian. This conclusion is justified by experimental evidence, because at the leading edge of the wheel, the soil is elevated above the original level (bow wave) and tends to flow laterally. By definition, lateral flow is excluded within the bulldozing zone.

61. The reason that the origin of the parabolas was put at the bottom dead center $(\delta=0)$, was because the bulldozing zone at its real origin $(\delta=s \alpha)$ has to possess a certain real width; otherwise, it could not have been observed by Wong and Reece. ${ }^{14}$ This created a fictive portion of the bulldozing zone within the lunule zone (dashed lines, fig. 19b), which was not considered in the analysis.

\section{Lateral flow zone}

62. The two remaining portions of the contact area (fig. 19b) are termed zones of lateral flow because the soil particles beneath these zones are assumed to move strictly parallel to the vertical plane through the wheel axle. If there is lateral flow, the soil obviously is in a perfect plastic condition, but this does not necessarily imply that the shear stress in any direction is equal to its maximum value. In fact, even in a perfect plastic state, every value of shear stress between $\tau=0$ and 
$\tau=\tau_{\max }=\sigma \tan \phi$ can be obtained, depending on the orientation of the plane considered. The shear stress is zero in the planes of the principal stresses, and maximum on all rupture planes. Since there were no reasons to assume that the rolling surface of the wheel within the zones of lateral flow was a rupture surface, the $\tau / \sigma$ ratio may yield any value between zero and $\tan \phi$.

63. This is a major difference from the bulldozing zone, where the rolling surface was intuitively taken as a rupture surface. Since the pattern of rupture surfaces beneath the zones of lateral flow is unknown, the shear stress at the rolling surface cannot be assessed. It was assumed that the ratio of the real shear stress to the maximum shear stress at the rolling surface yields a constant value $\lambda$ throughout the zone of lateral flow:

$$
\tau=\lambda \tau_{\max }=\lambda \sigma \tan \varnothing
$$

where $\lambda$ is an experimental constant.

64. Another fundamental difference between the zone of lateral flow and the bulldozing zone is that the real shear stress vector does not fall into the vertical plane of travel, but has a significant lateral component aue to soil flow.

65. Since only the tangential component in the vertical plane of travel of the shear stress vector contributes to the pull and torque characteristics of the wheel, the effective shear stress (i.e. tangential. to the wheel perimeter) is

$$
\tau_{\mathrm{F}}=\tau \cos \gamma=\lambda \tau_{\max } \cos \gamma=\lambda \sigma \tan \phi \cos \gamma
$$

where $\gamma$ is the angle of inclination of the $\tau$ vector with respect to the vertical plane of travel.

66. In other words, the effective shear stress $\tau_{F}$ within the zones of lateral flow is reduced with respect to $\tau_{\max }$ for two reasons: (a) the $\tau_{\max }$ vector has a radial component, accounted for by the coefficient $\lambda$; (b) the $\tau_{\max }$ vector also has a lateral component, accounted 
for by the $\cos \gamma$ term. At present, there is no way to assess the numerical value of $\lambda$, but the angle $\gamma$ might be roughly evaluated by the following reasoning.

67. A local velocity vector $v_{p}$ can be attributed to every point of the rolling surface (fig. 20a). This velocity vector is perpendicular

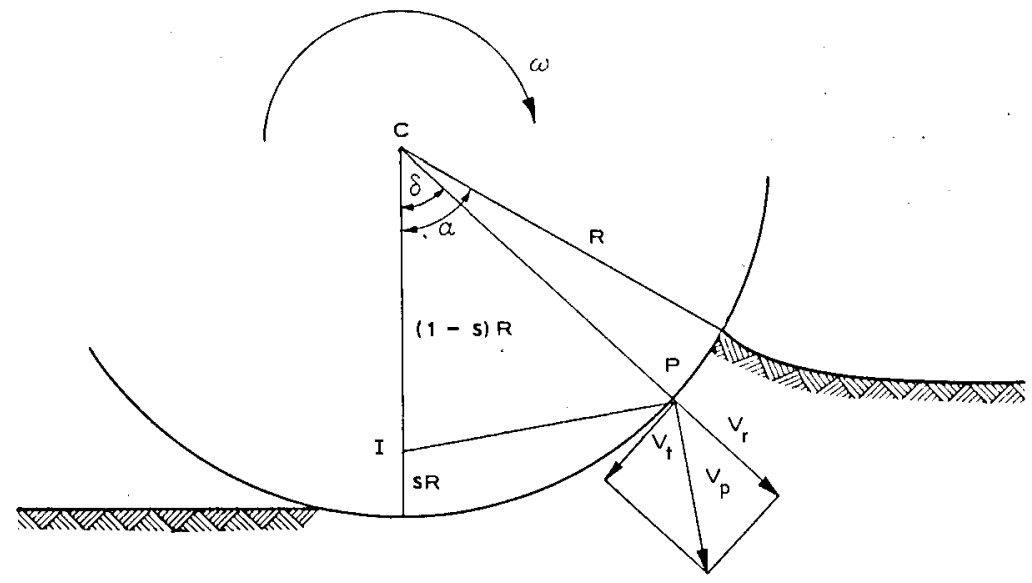

a.

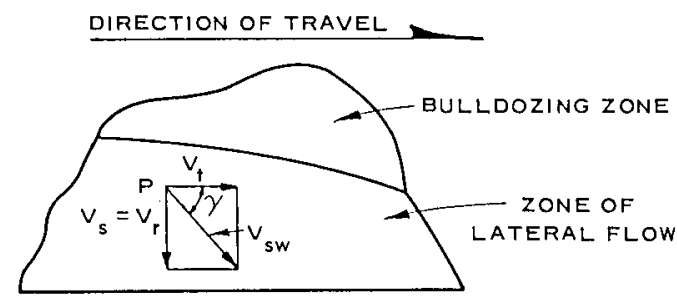

b.

Fig. 20. Schematic diagram of soil-wheel velocity vectors

to the line connecting the instantaneous center of rotation $I$ with the point $\mathrm{P}$ in question, and its magnitude is $\omega$ times the length of the line IP.

68. The velocity vector $v_{p}$ can be separated into its tangential $\left(v_{t}\right)$ and radial $\left(v_{r}\right)$ components, which are (fig. 20)

$$
\begin{aligned}
& v_{t}=\operatorname{R\omega }[1-(1-s) \cos \delta] \\
& v_{r}=\operatorname{R\omega }(1-s) \sin \delta
\end{aligned}
$$


Only the wheel displacements due to $\mathrm{v}_{r}$ push the soil away from under the wheel, while tangential wheel displacement is a pure sliding process with respect to the adjacent soil. The direction of the soil movements has already been assumed to be purely lateral. It is further hypothesized that the mean horizontal velocity of the moving soil particles $v_{S}$ is equal to the radial wheel velocity that causes the soil to move:

$$
v_{s}=v_{r}=\operatorname{R\omega }(1-s) \sin \delta
$$

Thus, the actual soil-to-wheel sliding velocity $\mathrm{v}_{\mathrm{SW}}$ is the sum of the vectors in the plane of the rolling surface of the two velocities that contribute to it, i.e. $v_{s}$ and $v_{t}$ (fig. 20b).*

$$
\vec{v}_{S W}=\vec{v}_{S}+\vec{v}_{t}
$$

Since the orientation of the soil-to-wheel shear stress vector $\tau$ is the same as that of the soil-to-wheel sliding velocity vector, its inclination with respect to the vertical plane of travel is (fig. 20b)

$$
\tan \gamma=\frac{v_{s}}{v_{t}}=\frac{v_{r}}{v_{t}}=\frac{(1-s) \sin \delta}{1-(1-s) \cos \delta}
$$

Hence,

$$
\cos \gamma=\frac{1}{\sqrt{1+\tan ^{2} \gamma}}=\frac{1-(1-s) \cos \delta}{\sqrt{[1-(1-s) \cos \delta]^{2}+[(1-s) \sin \delta]^{2}}}
$$

According to equations 20 and 25,

$$
t_{F}=\frac{{ }^{T} F}{\sigma}=\frac{\lambda[1-(1-s) \cos \delta]}{\sqrt{[1-(1-s) \cos \delta]^{2}+[(1-s) \sin \delta]^{2}}} \tan \phi
$$

* The vector $v_{t}$ is drawn in the opposite sense than in fig. 20a. It represents here the relative velocity of the soil with respect to the wheel surface. 
where $t_{F}$ is the effective $t$ value in the zone of lateral flow. 69. The combined width of both zones of lateral flow (fig. 19b, equation 18) can be expressed by

$$
\mathrm{w}_{\mathrm{F}}=\mathrm{b}-\mathrm{w}_{\mathrm{B}}=\mathrm{b}(1-\delta)^{2}
$$

The length of the two lateral zones as well as that of the bulldozing zone is (fig. 19)

$$
\ell_{F}=l_{B}=(I-s) R \alpha
$$

Plastic and elastic regions

70. For the remainder of the analysis, the bulldozing zone and both lateral zones will be treated jointly. Together, they constitute the principal forward or plastic region because the adjacent soil is in a plastic state. Correspondingly, the principal rearward region, which is equivalent to the lunule zone, is the elastic region (fig. 19).

71. From equations 17, 18, 26, and 27, the average $t$ value in the plastic region, taken over the wheel width, is

$$
\begin{gathered}
t_{a}=\frac{1}{b}\left(w_{F F} t_{F}+w_{B} t_{B}\right) \\
t_{a}=\left[\frac{\lambda\left(1-\delta^{2}\right)[1-(1-s) \cos \delta]}{\sqrt{[1-(1-s) \cos \delta]^{2}+[(1-s) \sin \delta]^{2}}}+\delta^{2}\right] \tan \phi
\end{gathered}
$$

A similar equation that describes the variation of $t$ in the rearward elastic zone is not available. It is assumed that equation 16, which is the measurement at the bottom dead center $(\delta=0)$, can be considered as the mean $\tau / \sigma$ value over the total elastic zone.

72. Equations 16 and 29 are represented in figs. 21 and 22 using the following numerical values:

$$
\begin{aligned}
\tan \phi & =0.5 \text { (reference value) } \\
m & =0.05 \text { (experimental value, figs. } 6 \text { and } 7)
\end{aligned}
$$


Fig. 21. Theoretical $t$ distribution at soilwheel interface, $\lambda=0.4$
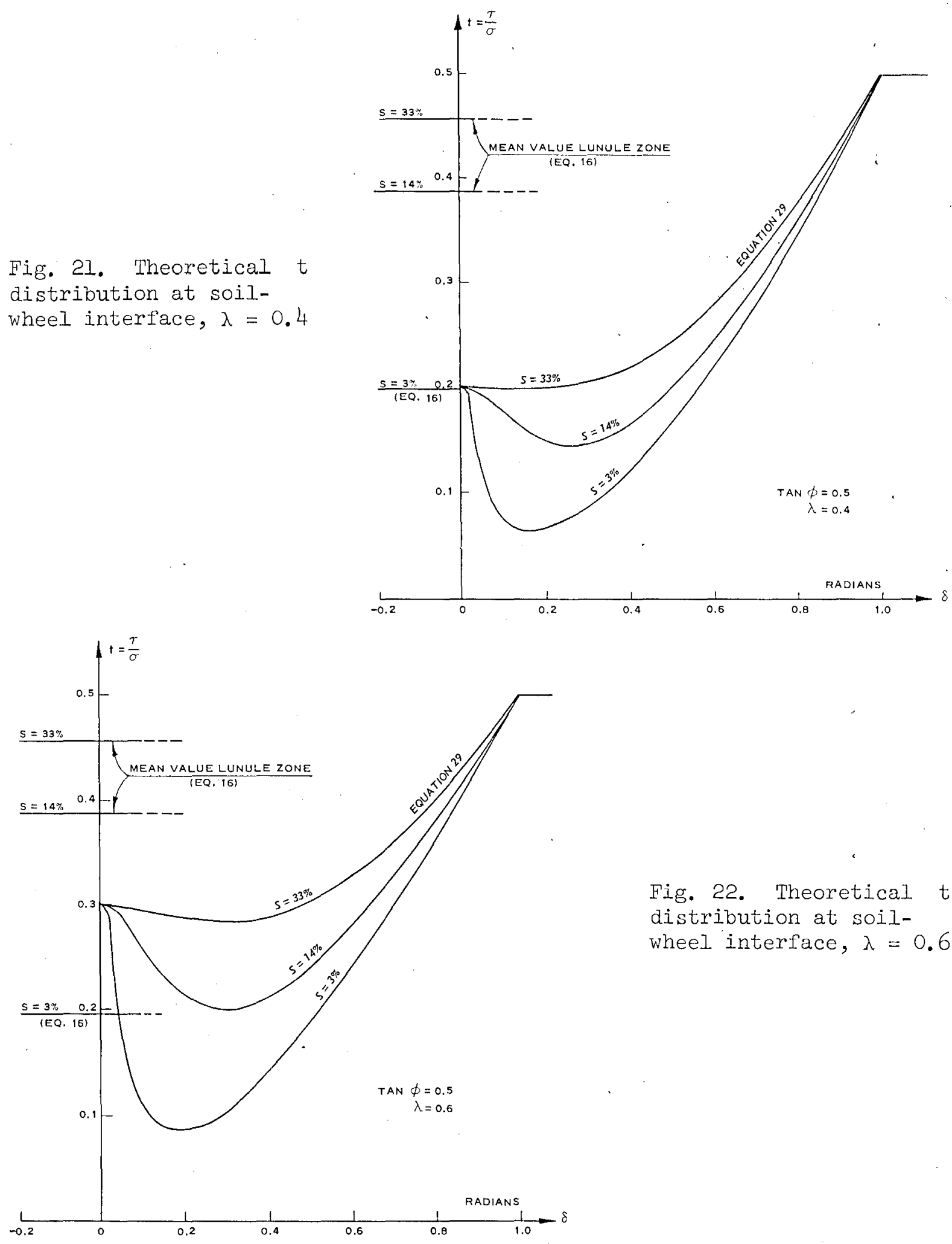

Fig. 22. Theoretical $t$ distribution at soilwheel interface, $\lambda=0.6$ 


$$
\begin{aligned}
& \lambda=0.4,0.6 \\
& s=3 \%, 14 \%, 33 \%
\end{aligned}
$$

where $\lambda$ is an experimental coefficient; the numerical values of 0.4 and 0.6 were chosen as a first trial.

\section{Theoretical and Experimental Results Compared}

\section{Using New Concept}

73. The theoretical $t_{m}$ values derived using the proposed approach were compared with the experimental $\mathrm{M} / \mathrm{RW}$ values using equations $1 \mathrm{la}$ and $12 \mathrm{~b}$ in the same manner as was done previously using Sela's theory. Examples of the graphs from which the overall mean $t_{m}$ values were determined are given in fig. 23. These plots also show that for higher contact angles, the variation of the $t$ ratio generally corresponds with Sela's experimental data, i.e., high $t$ values at both ends of the contact length, minimum value near the middle. For small contact angles $(\alpha+\beta<0.5)$, which were not investigated by sela, the t-variation tended to increase from the leading edge toward the rear end of the contact length.

74. The variations of $t_{m}$ with the contact angle $(\alpha+\beta)$ are illustrated in fig. 24.* The theoretical $t_{m}$ curves drawn with $\lambda=0.4$ give somewhat lower values and exhibit a slightly steeper increase in their ascending portion than the curves of $\lambda=0.6$. When these theoretical curves are compared with the experimental results (figs. 11-14), it is apparent that the two sets of curves vary in almost the same manner, as required by equation $12 \mathrm{~b}$. In addition to the complete agreement of the . five qualitative features, a rather subtle feature of the experimental $\mathrm{M} / \mathrm{RW}$ curves is reflected by the $t_{m}$ curves: for $s=14$ percent, the minimum $\mathrm{M} / \mathrm{RW}$ value occurs at a higher contact angle than it does for the two other curves, except in fig. 11.

* To avoid confusion, it should be noted that fig. 23 represents the variation of $t$ as a function of the position angle $\delta$ for a given contact angle $(\alpha+\beta)$; fig. 24 gives the variation of $t_{m}$ as a function of the varying contact angle $(\alpha+\beta)$. 


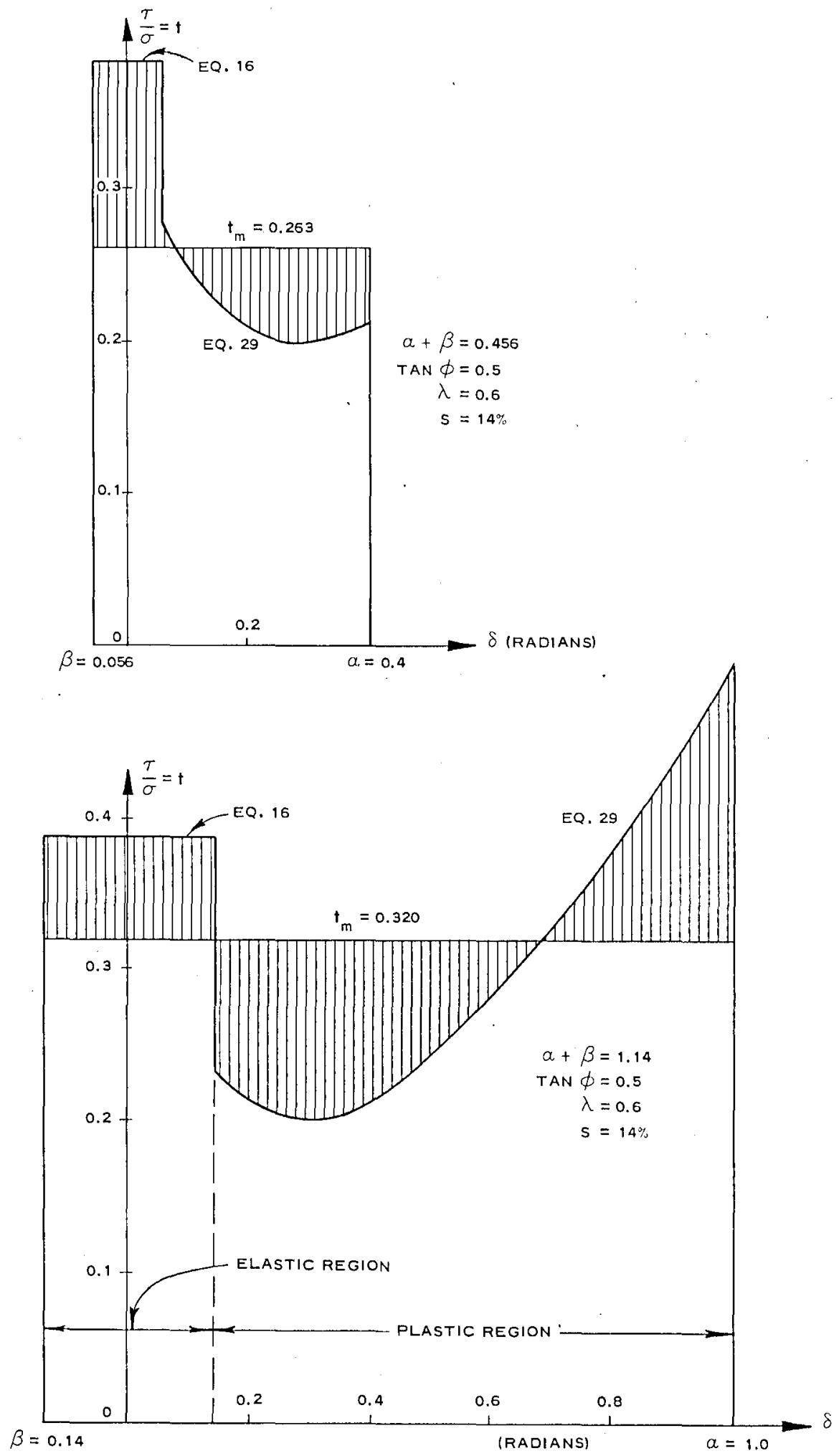

Fig. 23. Examples of graphs used to determine overall mean $t_{m}$ values 

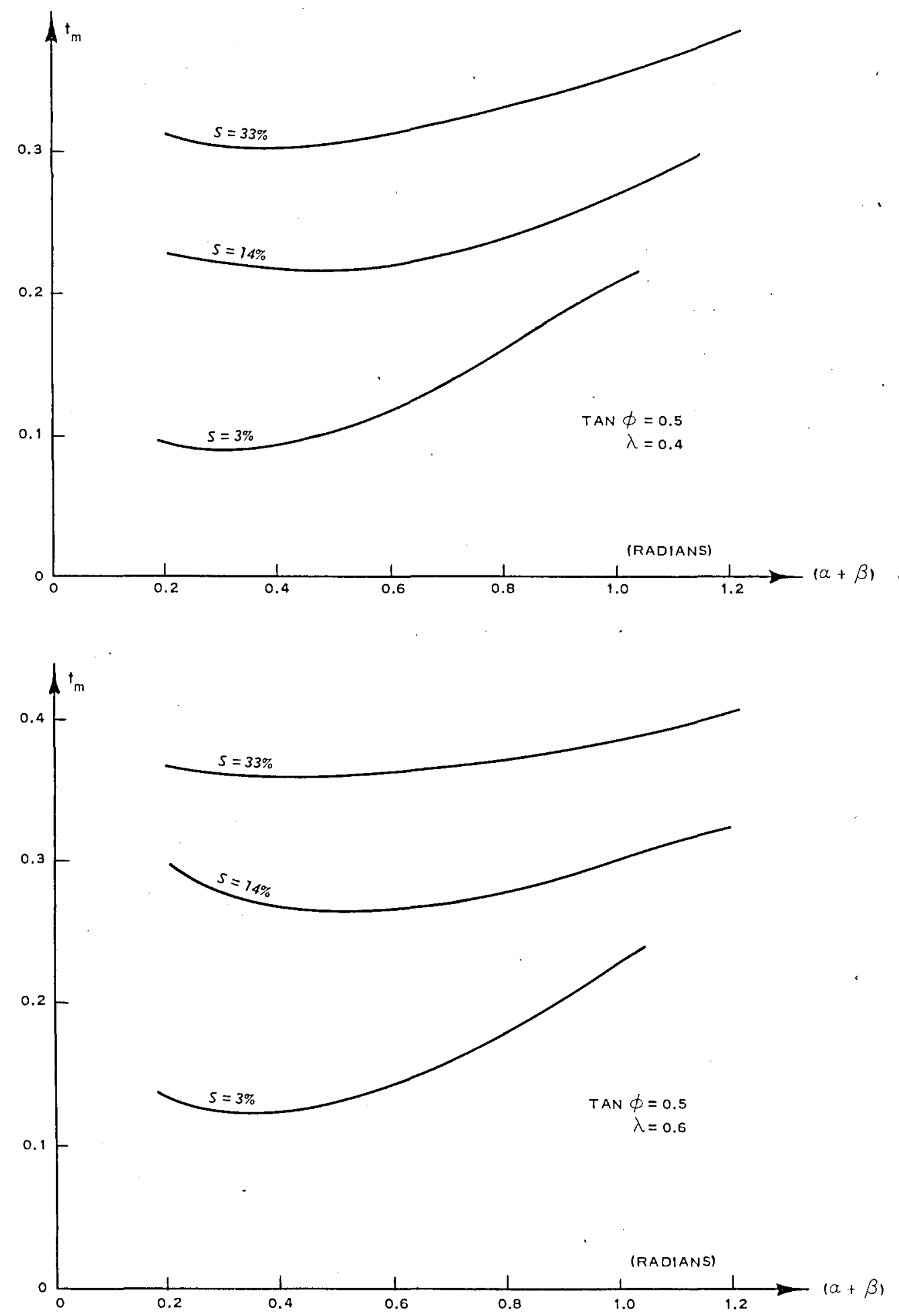

Fig. 24. Variations of $t_{m}$ with contact angle $(\alpha+\beta)$ 
75. As a second check; equation lla was applied to the proposed theory. It was found that, for tests run with a cone index of 60 , the $\lambda=0.4$ curves fit better; for a cone index of 30 , the $\lambda=0.6$ curves have a better fit. Using the appropriate $\lambda$ values and correcting the value of $\tan \varnothing$ as previously explained, the experimental $\mathrm{M} / \mathrm{RW}$ curves are plotted in figs. 25 and 26 , together with the theoretical $t_{m}$ curves and the \pm 25 percent error limits. With the exception of some portions of the 3 percent slip curves, the $M / R W$ curves fall within the theoretical bounds. Only a small percentage of the total length of all curves lies beyond the limits.* This small error percentage can be reduced even further by a more appropriate choice of the $\lambda$ value (see paragraph 79). There is good agreement between the theoretical values and the experimental findings. Thus, the basic idea leads to a reasonably valid approximation, at least for the range of conditions tested.

\section{Comparison of New Concept and Sela's Approach}

76. Many of the basic assumptions of the proposed approach are opposite to those made by sela. ${ }^{17}$ Sela's theory is essentially twodimensional (lateral flow is neglected); the new concept is based, to a great extent, on consideration of the lateral flow. Furthermore, an attempt was made to take into account the effect of the lunule, the existence of which was unknown at the time sela's theory was elaborated.

77. The most significant difference, however, is the rejection of the idea that the shear stress depends, among other factors, on the "distance from the point in question to the leading edge of the contact area." 17 When this is assumed, the maximum $\tau / \sigma$ ratio is never reached, even at 100 percent slip, which contradicts common sense. Under the new concept, equations 14 and 15 indicate that for 100 percent slip, $\tau / \sigma$ $=\tan \phi$ over the total area of the wheel-soil interface. However, the theoretical concept developed herein is not proposed as a final answer

* As explained for Sela's results, this exror percentage would not change significantly if the experimental M/RW curves were shifted slightly to the right to compensate for the faulty measurement of contact length. 

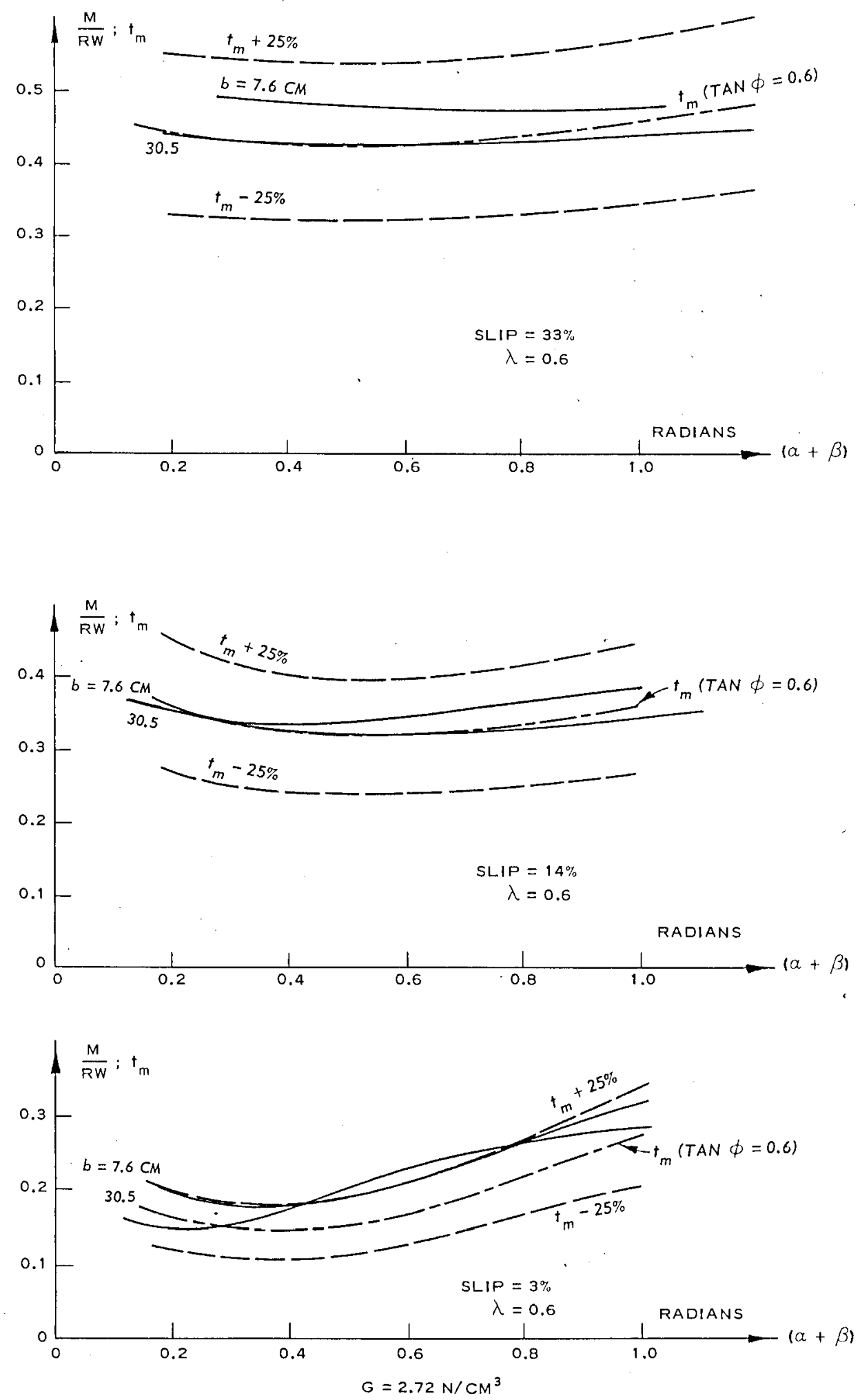

Fig. 25. Corrected $t_{m}$ curves with $+25 \%$ error limits superimposed on corresponding $\mathrm{M} / \mathrm{RW}$ curves, $\lambda=0.6$ 

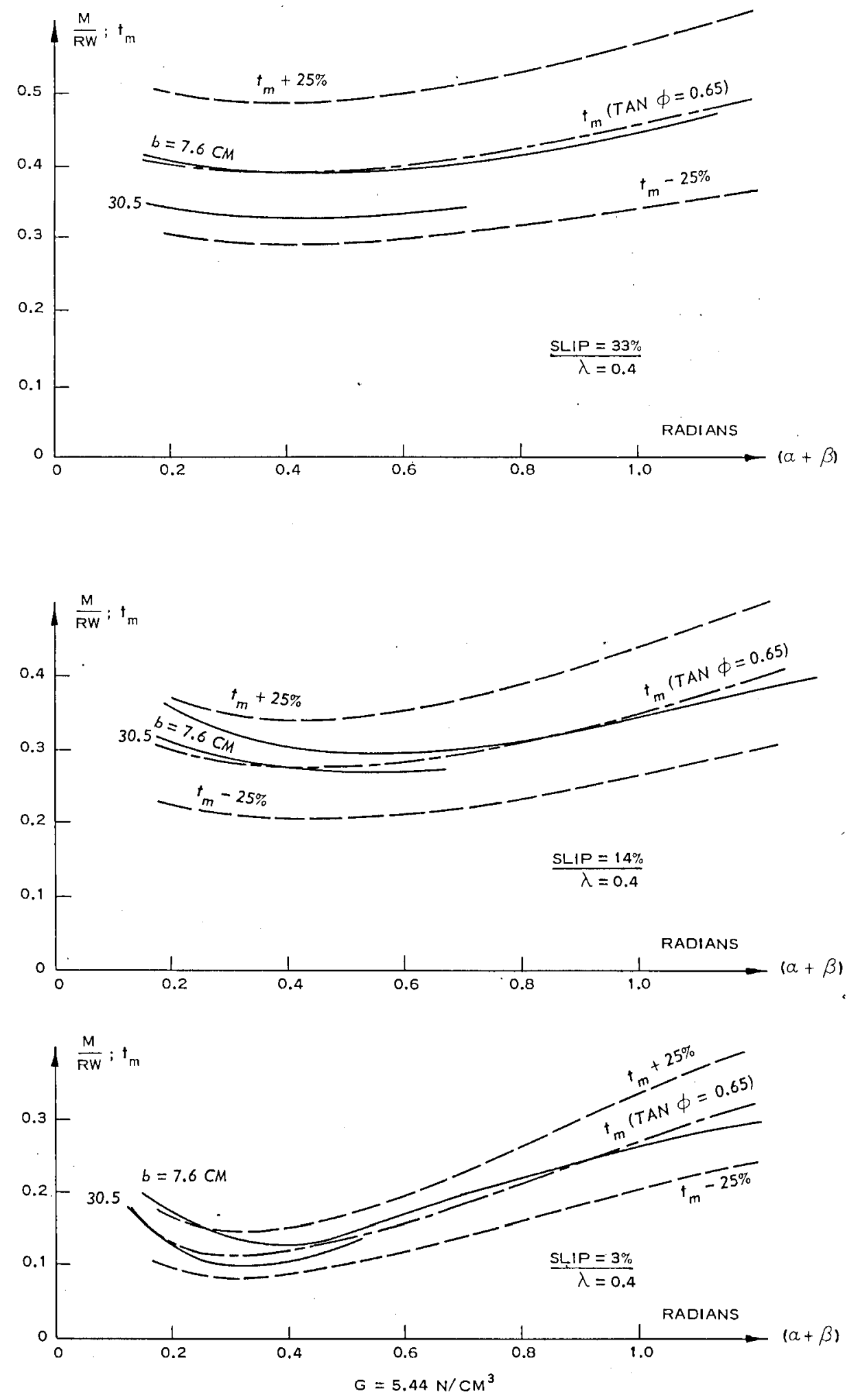

Fig. 26. Corrected $t_{m}$ curves with $+25 \%$ error limits superimposed on corresponaing $\mathrm{M} / \mathrm{RW}$ curves, $\lambda=0.4$ 
to the problem of the soil-wheel interaction. Some very crude assumptions had to be made that will require revision as additional data are accumulated. Rather, this concept is intended to demonstrate that an entirely different approach is possible.

78. The most controversial assumption of the new concept is that of a constant $\lambda$ value valid over the whole zone of lateral flow. It should be remembered here that the parameter $\lambda$ was introduced in an attempt to comprehend the influence of a complex physical phenomenon--the rupture pattern beneath the zone of lateral flow--by a single constant. This hypothesis, however, makes the approach very flexible because the parameter $\lambda$ is an experimental coefficient and can be chosen so that the theoretical $t_{m}$ curves approach the $M / R W$ curves even closer than in figs. 25 and 26. The form of the $t_{m}$ curves is not changed significantly by a varying $\lambda$ (fig. 24), but the position is. As $\lambda$ increases, the $t_{m}$ curve shifts upward. Thus, the somewhat unexpected lower M/RW values at higher cone index ratings (compare figs. 13 and 11 ; 14 and 12). could effectively be dealt with by associating the lower of the two $\lambda$ values with the higher soil strength and vice versa.

79. Even if further investigations verify this concept of a constant $\lambda$ value over the whole zone of lateral flow, it is probable that $\lambda$ varies not only with soil strength, but also with slip, wheel geometry, and load. The determination of $\lambda$ can be refined using available test data. For example, the narrow wheel appears to develop a higher $M / R W$ ratio than the wide wheel (compare figs. 11 and 12 with figs. 13 and 14 ). Hence, $\lambda$ decreases as wheel width increases. By similar arrangement, an almost perfect quantitative coincidence of $t_{m}$ and $M / R W$ curves could be obtained for the 3 percent slip condition, instead of the rather poor agreement between curves for the chosen values of $\lambda$ shown in figs. 25 and 26.

80. Such considerations, however, are somewhat premature. This concept should be thoroughly investigated, and hopefully, the basic assumptions refined, before a definite pattern of numerical values is established. 


\section{Conclusions}

81. The following conclusions are believed warranted by the findings of this report:

a. The shear stress-displacement relation for soils (equation 2 or similar ones) is inadequate for describing the soil-wheel interaction, or for predicting wheel performance.

b. The mean shear-to-normal stress ratio $t_{m}$ at the wheelsoil interface is closely related to the $\mathrm{M} / \mathrm{RW}$ ratio (equations $11 \mathrm{la}$ and $12 \mathrm{~b}$ ), and can be used to experimentally determine the validity of any $\tau / \sigma$ theory more accurately than can be done using direct measurements of the tangential and normal stresses.

c. A new concept, based on the real soil rupture pattern beneath rigid wheels, provides a sound approach for determining the $\tau / \sigma$ ratio.

\section{Recommendations}

82. It is recommended that:

a. Experimental and theoretical research be conducted to study the flow pattern beneath rigid wheels, especially the three-dimensional features of the pattern. By using a rigid wheel with a transparent rolling surface, the flow pattern immediately beneath the wheel could be photographed from inside the wheel. Thus, the assumptions concerning the different zones at the wheel-soil interface could be checked directly and refined.

b. Investigations of the $\tau / \sigma$ ratio, similar to those reported here, be made using cohesive soil.

c. In conjunction with the research on the $\tau / \sigma$ ratio, systematic measurements be made of the variations of the normal stresses within the wheel-soil interface, and these variations be analytically expressed. Once the normal stress and the $\tau / \sigma$ ratio can be predicted, the theoretical problems of soil-wheel mechanics for rigid wheels can be considered solved. This solution appears to be prerequisite to considering the more complex problems of deformable tires on soft soils from other than a purely empirical point of view. 
1. Bekker, M. G., Theory of Land Locomotion; The Mechanics of Vehicle Mobility, The University of Michigan Press, Ann Arbor, Mich., 1956.

2. Janosi, Z. and Hanamoto, B., "The Analytical Determination of Drawbar Pull as a Function of Slip for Tracked Vehicles in Deformable Soils," Proceedings of the First International Conference on the Mechanics of Soil-Vehicle Systems, Torino, Italy, June 1961, pp 707736 .

3. Drucker, D. C., "On Stress-Strain Relations for Soils and Load Carrying Capacity," Proceedings of the First International Conference on the Mechanics of Soil-Vehicle Systems, Torino, Italy, June 196I; pp 15-27.

4. Wills, B. M. D., "The Measurement of Soil Shear Strength and Deformation Moduli and a Comparison of the Actual and Theoretical Performance of a Family of Rigid Tracks," Journal of Agricultural Engineering Research, Vol 8, No. 2, 1963, pp 115-131.

5. Deresiewicz, H., "A Review of Some Recent Studies of the Mechanical Behavior of Granular Media," Applied Mechanic's Review, Vol 11, 1958, pp 259-261.

6. Kézdi, A., "Grundlagen Einer Allgemeinen Bodenphysik," VDI-Zeitschrift, Vol 108, Feb 1966, pp 161-166.

7. Green, A. E. and Rivlin, R. S., "The Mechanics of Materials with Structure," Rheology and Soil Mechanics, Springer-Verlag, Beríin, 1966, pp 1-7.

8. Berry, D. S., "A Discussion of the 'Stochastic' Theory of Ground Movement," Felsmechanik u. Ingenieurgeologie, Vol II, 1964, pp 213227.

9. Murayama, S., "A Theoretical Consideration on a Behavior of Sand," Rheology and Soil Mechanics, Springer-Verlag, Berlin, 1966, pp 146159.

10. Smoltczyk, H. U., "Stress Computation in Soil Media," Journal of the Soil Mechanics and Foundations Division; Proceedings of the American Society of Civil Engineers, Vol 93, No. SM2, March 1967, pp 101-124.

11. Wiendieck, K., "Zur Struktur Körniger Medien," Die Bautechnik, Vol 44, 1967, pp 196-199.

12. Reece, A. R., "Principles of Soil-Vehicle Mechanics," Proceedings of the Institution of Mechanical Ingineers, Vol 180, Part 2A, 1965-66. 
13. Boucherie, M., "Evolution de Roues Rigides en Milieus Pulverulents a Deux et Trois Dimensions," Thesis, Fac. d Sciences, Grenoble, 1964.

14. Wong, J. Y. and Reece, A. R., "Soil Failure Beneath Rigid Wheels," Proceedings of the Second International Conference of the International Society for Terrain-Vehicle Systems, Canada, 1966, pp 425445.

15. Biarez, J." "Contribution à I'Étude des Propriétés Mécaniques des sols et des Matériaux Pulvérulents," Thesis, Fac. a Sciences, Grenoble, 1962 .

16. Wiendieck, K., "Zur Standsicherheit unverankerter spundwände," Die Bautechnik, Vol 39, 1962, pp 369-373.

17. Sela, A. D., "The Shear to Normal Stress Relationship Between a Rigid Wheel and Dry Sand," Report No.'8524, June 1964, U. S. Army TankAutomotive Center, Warren, Mich.

18. MeRae, J. I., Powell, C. J., and Wismer, R. D., "Performance of Soils Under Tire Loads; Test Facilities and Techniques," Technical Report No. 3-666, Report 1, Jan 1965, U. S. Army Fngineer Waterways Experiment Station, CE, Vicksburg, Miss. 
Tablc 1

Theoratical M/RW Values for Various Assumed $\sigma$ and $t$ Distributions

\begin{tabular}{|c|c|c|c|c|c|c|c|c|c|c|c|c|c|c|c|c|c|c|c|c|c|}
\hline \multirow[b]{2}{*}{${ }_{m}$} & \multirow[b]{2}{*}{$\alpha$} & \multicolumn{20}{|c|}{$M / R W$} \\
\hline & & $\Lambda 1$ & $\Lambda 2$ & $\Lambda 3$ & A. 4 & A. & $\mathrm{B} 1$ & $\overline{B 2}$ & $\overline{\mathrm{B} 3}$ & B4 & B5 & $\mathrm{Cl}$ & $\mathrm{C} 2$ & $\mathrm{C} 3$ & $\mathrm{C} 4$ & C5 & $\mathrm{DI}$ & $D 2$ & D3 & 14 & $\overline{D s}$ \\
\hline \multirow{6}{*}{.1} & 0.1 & .0997 & 0.0999 & 0.0995 & 0.0997 & 0.0999 & 0.0998 & .1232 & 0.0783 & 0.1044 & 0.0966 & 0.0996 & 0.0784 & 0.1226 & 0.1043 & 0.0963 & 0.0997 & 0.1044 & 0.1043 & 0.1228 & .0327 \\
\hline & 0.3 & .1001 & 0.1005 & 0.0995 & 0.1000 & .1002 & .0999 & $.1231_{4}$ & .0783 & .1043 & 0.0968 & 0.1001 & 0.0792 & 0.1226 & 0.1049 & 0.0367 & 0.0998 & 0.1047 & 0.1041 & 0.1228 & .0329 \\
\hline & 0.5 & 1015 & 0.1023 & .1007 & 0.1015 & 0.1017 & 1006 & 1243 & .0786 & 1048 & .0975 & .1022 & .0813 & 0.1246 & $0.10^{\prime} 73$ & 0.0987 & 0.1009 & .1060 & .1050 & 0.1238 & 0839 \\
\hline & 0.7 & 1042 & 1053 & .1030 & $10^{\prime}+1$ & 1044 & 1018 & 1258 & .0795 & 1059 & .0988 & 0.1062 & .0848 & 0.1288 & 0.1115 & 0.1024 & 0.1029 & 0.10832 & 1068 & .1260 & 0857 \\
\hline & 0.9 & 1032 & 1097 & 0.1065 & 0.1080 & 0.1084 & 1035 & 1281 & .0807 & 0.1075 & .1007 & 0.1122 & .0901 & 0.1354 & .1178 & .1081 & 0.1059 & 0.111 .5 & .1097 & .1294 & .0883 \\
\hline & 1.1 & 2136 & 1156 & 1116 & 11.34 & 1.139 & 060 & 1312 & 0825 & .098 & 1032 & 1208 & 9976 & 1451 & 1269 & 64 & 1.100 & 1161 & 1138 & .1342 & 0920 \\
\hline \multirow{6}{*}{0.3} & .1 & 969 & 2932 & 2953 & 2967 & 2973 & 2981 & 3680 & 2335 & 3112 & 2887 & 2956 & 2338 & 3620 & 3099 & 2854 & 2968 & 3113 & 3096 & .3649 & .2465 \\
\hline & 0.3 & .2932 & 0.2973 & 0.2889 & .2930 & 2937 & 2956 & 3659 & 2305 & 3070 & 0.2874 & 0.2906 & .2331 & 0.3514 & 0.3054 & $0.2\{300$ & 0.2925 & 0.3082 & .3032 & .3578 & .2439 \\
\hline & 0.5 & 0.2929 & 0.2998 & 0.2861 & 0.2927 & 0.2934 & $0.294 ?$ & 0.3657 & 0.2288 & 0.3046 & 0.2877 & 0.2903 & 0.2362 & 0.3468 & 0.3059 & 0.2793 & 0.2910 & 0.3079 & 0.2998 & 0.3561 & 0.2437 \\
\hline & 0.7 & 0.2960 & 0.3056 & 0.2866 & 0.2956 & 0.2966 & .2956 & 0.3676 & .2285 & 3039 & 0.2896 & 0.2348 & 0.2432 & 0.3480 & 0.3113 & 0.2831 & 0.2922 & $0.310 \%$ & 0.2992 & 0.3536 & .2457 \\
\hline & 0.9 & 0.3025 & 0.3150 & 0.2905 & 0.3017 & 0.3034 & 2981 & 3715 & .2295. & 0.3049 & 0.2932 & 0.3043 & .2546 & 0.3549 & 0.3218 & 2920 & 2961 & 3157 & .3015 & .3563 & .2500 \\
\hline & 1.1 & .31 .28 & 0.32834 & .2978 & 3114 & .3141 & 0.3024 & .3774 & 0.2318 & 0.3076 & 0.2986 & 3195 & 2711 & 0.3682 & 0.3381 & .3064 & 0.3029 & 3240 & 3066 & .3623 & 2569 \\
\hline \multirow{6}{*}{0.} & 0.1 & 0.4909 & 0.4916 & 4867 & 4906 & 4916 & 4945 & 6111 & 3867 & 154 & 4796 & 4872 & 3872 & .5942 & 0.51 .12 & .4701 & 0.4908 & 5156 & 5108 & .6024 & .4082 \\
\hline & 0.3 & 0.4776 & 0.4887 & 0.4665 & 0.4773 & 0.4783 & 4859 & 0.6029 & $.37 \% 2$ & 0.5022 & 0.4742 & 0.4691 & 0.3815 & 0.5605 & 0.4943 & 0.4511 & 0.4764 & $0.504+1$ & 0.4908 & 0.5793 & 3988 \\
\hline & 0.5 & 0.4702 & 0.4882 & 0.4530 & 0.4697 & 0.4711 & 0.4803 & 0.5982 & 0.3702 & 0.4924 & 0.4716 & 0.4594 & 0.3819 & 0.5389 & 0.4860 & 0.4406 & 0.4672 & 0.4976 & 0.4766 & 0.5630 & 0.3936 \\
\hline & 0.7 & 0.4685 & 0.4932 & 0.4455 & 0.4676 & 0.4697 & 0.4776 & 0.5969 & 0.3657 & 0.4857 & .4718 & 0.4575 & .3882 & 0.5274 & 0.4853 & $0.4+378$ & 0.4625 & 0.4956 & 0.4677 & 0.5537 & 0.3921 \\
\hline & 0.9 & 0.4722 & 0.5036 & 0.4436 & 0.4704 & 0.4740 & 0.4776 & 0.5989 & .3634 & 0.4819 & 0.4748 & 0.4630 & 0.4009 & 0.5251 & 0.49222 & $0.44+24$ & 0.4623 & 0.4980 & 0.4635 & 0.5488 & 0.3944 \\
\hline & 1.1 & 0.4815 & 0.5198 & 0.4472 & 0.4784 & 0.4844 & 0.4805 & 0.6042 & 0.3634 & 0.4809 & 0.4806 & 0.4763 & 0.4207 & 0.5317 & 0.5067 & 0.4549 & 0.4663 & 0.5048 & 0.4638 & 0.5489 & 0.40 \\
\hline
\end{tabular}


Commanding General, U. S. Army Materiel Command

ATTPN: AMCRD-DM

AMCRD-TV

Washington, D. C.

Commanding Officer, USACRREL

ATIN: Library

Hanover, N. H.

Commanding Officer, U. S. Army Mobility Equipment

Research and Development Center

ATTN: Technical Document Center

Fort Belvoir, Va.

Commanding Officer, USA Electronics Command

Meteorological Support Activity

Fort Huachuca, Ariz.

Commanding Officer, USA Electronics Research and

Development Laboratories

ATTIN: SELRA/ADT

Fort Monmouth, N. J.

Chief of Research and Development

AIIT: Chief, Combat Materiel Division

Department of the Army

Washington, D. C.

Chief of Research and Development

ATINT: CRDES, Department of the Army

Washington, D. C.

Chief of Research and Development

3 copies

Headquarters, Department of the Army

of Form

ATTN: Director of Army Technical Information

1473

Washington, D. C.

Defense Intelligence Agency

ATTN: DIAAP-IE2

Washington, D. C. 
Director, OSD/ARPA Regional Field Office ARMISH-MAAG (RFO-I)

APO New York 09205

Commanding Officer, U. S. Army Arctic Test Center

APO Seattle, Wash.

Chief of Engineers

ATIN: ENGTE-E

ENGAS - I

EIIGMC - ER

Department of the Army

Washington, D. C.

OCE (ENGTE) (for Engineer Standardization Program)

War Plans Division, Engineer Strategic Studies Group

Office, Chief of Engineers, U. S. Army

Erskin Hall, Army Map Service

Washington, D. C.

Commander, U. S. Army Combat Development Command Engineer Agency

ATTN: CSGENN-M

Fort Belvoir, Va.

The Librarian, U. S. Army Engineer School Library.

Thayer Hall

Fort Belvoir, Va.

USA Engr School

ATTN: Heavy Construction Section, Department of Engineering

Pavements and Materials Group

Fort Belvoir, Va.

Commanding General, XVIII Airborne Corps

ATTN: Corps Engineer

Fort Bragg, N. C.

Commanding officer

326th Engineer Battalion

Fort Campbel1, Ky.

Senior Engineer Instructor, office of Military. Instruction

United States Corps of Cadets

West Point, N. Y. 
President, U. S. Army Armor Board

Fort Knox, Ky.

President, U. S. Army Artillery Board

Fort Sill, Okla.

President, U. S. Army Infantry Board

Fort Benning, Ga.

Commanding General, U. S. Army Weapons Command

ATIN: AMSWE-RDR

Rock Island, Ill.

Commanding General, U. S. Army Tank-Automotive Center

ATTN: AMSTA-BSI

Warren, Mich.

Commander, U. S. Army Forces Southern Command

ATTN: Engineer

Fort Amador, Canal Zone

Commanding General, U. S. Continental Army Command

Engineer Division, DCSLOG

ATIT: ATLOG-E-MB

Fort Monroe, Va.

Commanding General, U. S. Continental Army Command

ATTN: ATIT-RD

Fort Monroe, Va.

Commandant, Command and General Staff College

ATTN: Archives

Fort Leavenworth, Kans.

Commanding General, U. S. Army Tank-Automotive Center

Technical Data Division

ATIN : AMSTA-TD

Warren, Mich.

Commander, U. S. Army Picatinny Arsenal

ATIN: SMUPA-VCl, Mr. D. Sen

Dover, N. J.

Commanding Officer, Yuma Proving Ground

ATTN : STEYP-TGM

Yuma, Ariz. 
Technical Library, Branch No. 4

U. S. Army Limited War Iaboratory

Aberdeen Proving Ground, Md.

Automotive Engineering Laboratory

ATTN: STEAP-DP-LU

Aberdeen Proving Ground, Ma.

Director, Development and Proof Services

ATTN : STEAP-DS-TU

Aberdeen Proving Ground, Ma.

Commanding Officer

ATIN: Tech Library, Bldg 313

Aberdeen Proving Gruund, Ma.

Commanding Officer, U. S. Army General Equipment Test Activity

Fort Lee, Va.

Chief, Crops Division, U. S. Army Biological Laboratories

Fort Detrick, Md.

Commanding Officer, U. S. Army Combat Developments

Comand Transportation Agency

ATTN: Mr. Earl S. Brown

Fort Eustis, Va.

Asst. Chief of Staff for Force Development

Hqs, Department of the Army, ATIN: FOR DS SSS

Washington, D. C.

United States Army Attaché, American Embassy

U. S. Navy 100, Box 36

Fleet Post Office

New York, IN. Y.

Office of Naval Research

ATIN: Geography Branch

Department of the Navy

Washington, D. C.

Commanding Officer, PHIBCB Two

U. S. Naval Amphibious Base

Iittle Creek, Norfolk, Va. 
Commanding Officer, PHIBCB One

U. S. Naval Amphibious Base

Coronado, San Diego, Calif.

Commanding Officer and Director

Naval Civil Engineering Laboratory

Port Hueneme, Calif.

Director, Naval Warfare Research Center

Stanford Research Institute

Menlo Park, Calif.

Commander, Naval Facilities Engineering Command

Navy Department, Code 03

Washington, D. C.

Commanding Officer, U. S. Naval. Photographic Interpretation Center

Washington, D. C.

Chief, Combat Service Support Division

Marine Corps Landing Force Development Center

Marine Corps Schools

Quantico, Va.

Commander, 3800th $\mathrm{AB}$ Wing, $\mathrm{AU}$

ATIN: BDCE-ED

Maxwell AFB, Ala.

Headquarters, USAF

(AFRSTC) Astronautics Division

DCS/Research and Development

Washington, D. C.

Cormmander, U. S. Strike Command

AIIN: J4-E

McDill AF'B, Fla.

Chief, Concepts and Evaluation Group

U. S. Strike Command

McDill AFB, Fla.

Commander, Air Proving Ground Center

ATTN: PGBPS-12

Eglin AF'B, Fla. 
Headquarters, Tactical Air Command

ATTN: DEPL

Langley AF'B, Va.

Headquarters, U. S. Air Force

Director of Civil Engineering (AFOCE-KA)

Washington, D. C.

Headquarters, USAF

Base Structures Branch, Directorate of Civil Engineering

ATIN: AFOCE-GC

Washington, D. C.

Commander, Hqs, Military Airlift Command

ATTN : MAMCE/FS

Scott AFB, III.

Commander, SEG (SEMSM)

Wright-Patterson AFB, Ohio

Air Force Weapons Laboratory

ATIN: Civil Engineering Branch

Kirtland AFB, N. Mex.

Terrestrial Sciences Lab (CRJT)

Air Force Cambridge Res Lab, L. G. Hanscom Field

Bedford, Mass.

Library, Division of Public Documents

U. S. Government Printing Office

Washington, D. C.

Library of Congress, Documents Expediting Project

Washington, D. C.

Defense Documentation Center

ATIN: Mr. Myer Kahn

Cameron Station

Alexandria, Va.

National Tillage Machinery Laborutory

U. S. Department of Agriculture

Auburn, Ala. 
Chief, World Soil Geography Unit, Soil Conservation Service

USDA, Room 233A Federal Center Bldg

Hyattsville, Md.

Chief, Crops Protection Branch

Crops Research Division, Agricultural Research Service

Beltsville, Ma.

Director, Pacific Southwest Forest and Range Experiment Station

ATIN: Henry W. Anderson

Berkeley, Calif.

U. S. Geological Survey

Chief, Source Material Unit, Branch of Military Geology

Washington, D. C.

Coastal Studies Institute

Louisiana State University

Baton Rouge, La.

Librarian, Bureau of Public Roads

U. S. Department of Commerce

Washington, D. C.

New York University

ATIN: Engineering Library

University Heights, Bronx, N. Y.

Professor I. C. Stuart

University of Michigan

Ann Arbor, Mich.

University of Arkansas, College of Engineering

ATTN: Mr. Henry H. Hicks, Jr.

Fayetteville, Ark.

Dr. Clark N. Crain, Director Project DUTY

Department of Geography, University of Denver

Denver, Colo.

Stanford Research Institute

ATTN: Mr. Gordon S. Wiley

Menlo Park, Calif. 
Engineering Societies Library

New York, N. Y.

Highway Research Board

Washington, D. C.

Research Analysis Corporation

AIIN: Iibrary

McLean, Va. 22101

Davidson Laboratory, Stevens Institute of Technology

ATrT: Dr. I. R. Ehrlich

Hoboken, N. J.

Center for Research and Engineering Science

University of Kansas

Lawrence, Kansas

Mr. David Sloss, Civil Engineering Department

University of Detroit

Detroit, Mich. 48221

Institute of Transportation and Traffic Engineering Library

University of California

Richmond, Calif. 94804

Wilson, Nuttall, Raimond Engineers, Inc.

ATTN : Library

Chestertown, Ma.

Battelle Memorial Institute

ATTN: RACIC

Columbus, Ohio 
(Security classification of thlle, body of abstract and indexing annotation must be ontered when tho overall repapt is closaltiod) 1. ORIGINATING ACTIVITY (CORPORale author)

U. S. Army Engineer Waterways. Experiment Station

Vicksburg, Mississippi

20. REPORT SECURITY CLASSIFICATION Unclassilied

REPORT TITLE

CONPIRIBUTION TO THE MTCIIAIICS OF RIGID WILEFS ON SAND

4. DESCRIPTIVE NOTES (TYPO of report and Inclusive dates),

Final report

5. AU THOR(S) (filrat name, middla Inillal, last namo)

Klaus W. Wiendieck

\begin{tabular}{|c|c|}
\hline $\begin{array}{r}\text { O. REPGRT DATE } \\
\text { MQY } 1968\end{array}$ & \begin{tabular}{c|c} 
7a. TOTAL NO. OFPAGES & 7B. NO. OF REFS \\
62 & 18
\end{tabular} \\
\hline $\begin{array}{l}\text { OA. CONTRACT OR GRANT NO. } \\
\text { b. PROJECT NO. } 1-V-0-14501-352 A \text {. }\end{array}$ & $\begin{array}{l}\text { 9. ORIGINATOR'S REPORT NUMBERISI } \\
\text { Tcchunical Report NO. M-6\}-2 }\end{array}$ \\
\hline $\begin{array}{l}\text { c. Task } 01 \\
\text { d. }\end{array}$ & 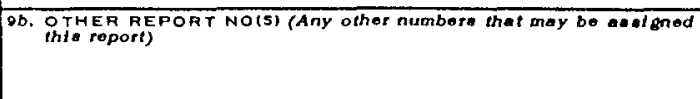 \\
\hline \multicolumn{2}{|c|}{ 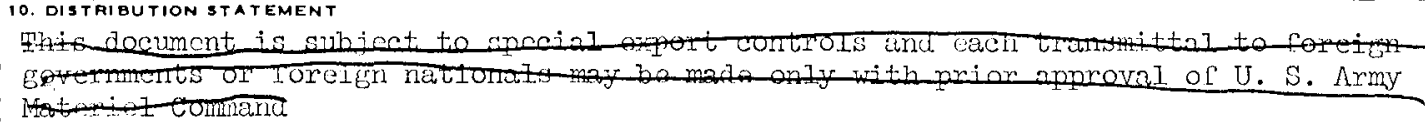 } \\
\hline 11. SUPPLEMEN TARY NOTES & $\begin{array}{l}\text { 12. SPONSORING MILITARY ACTIVITY } \\
\text { U. S. Army Materiel Command } \\
\text { Washington, D. C. }\end{array}$ \\
\hline
\end{tabular}

\section{ABSTRACT}

Current theoretical concepts of soil-running gear interaction are based on empirical pressure-sinkage and shear stress-displacement relations. However, tests from which these relations were obtained present a poor analogy to the soil-running gear interaction. In particular, use of the shear stress-displaccment relation for analytical evaluation of the shear stresses at the contact surface of rigid wheels on sand was found misleading, primarily because equations obtained by the bevameter or dragged plate tests describe soil behavior in in intermodiato stato betwoen the elastic and plastic states. Recent publications show that part of the soil close to a powered wheel is in an actual plastic flow state and part is in a quasielastic state. Thus, the soil-bevameter interaction is fundamentally different than the soil-wheel interaetion. Sela's theory of the relation between a rigid wheel and dry sand is based exclusivcly on the shear stress-displacement concept, and thus provided an excellent means of checking the concept. Using a simplo approximate relation between the $\mathrm{M} / \mathrm{NW}$ ratio and the mean shear-to-normal stress ratio $(\tau / \sigma)$ taken over the total contact surface, the theory was checked by means of constant-slip rigid wheel tests. Results strongly supported the conclusion that shear stress-displacement relations are irrelevant to soil-wheel mechanics. A new theory was developed that attempts to assess the variation of $\tau / \sigma$ along the soil-whecl interface, without referring to stressdisplacement relations. It uses the soil rupture pattern bencath rigid wheels on sand to subdivide the total interface into three zones of different soil behavior. This theory agrees better with test data than other theories. 


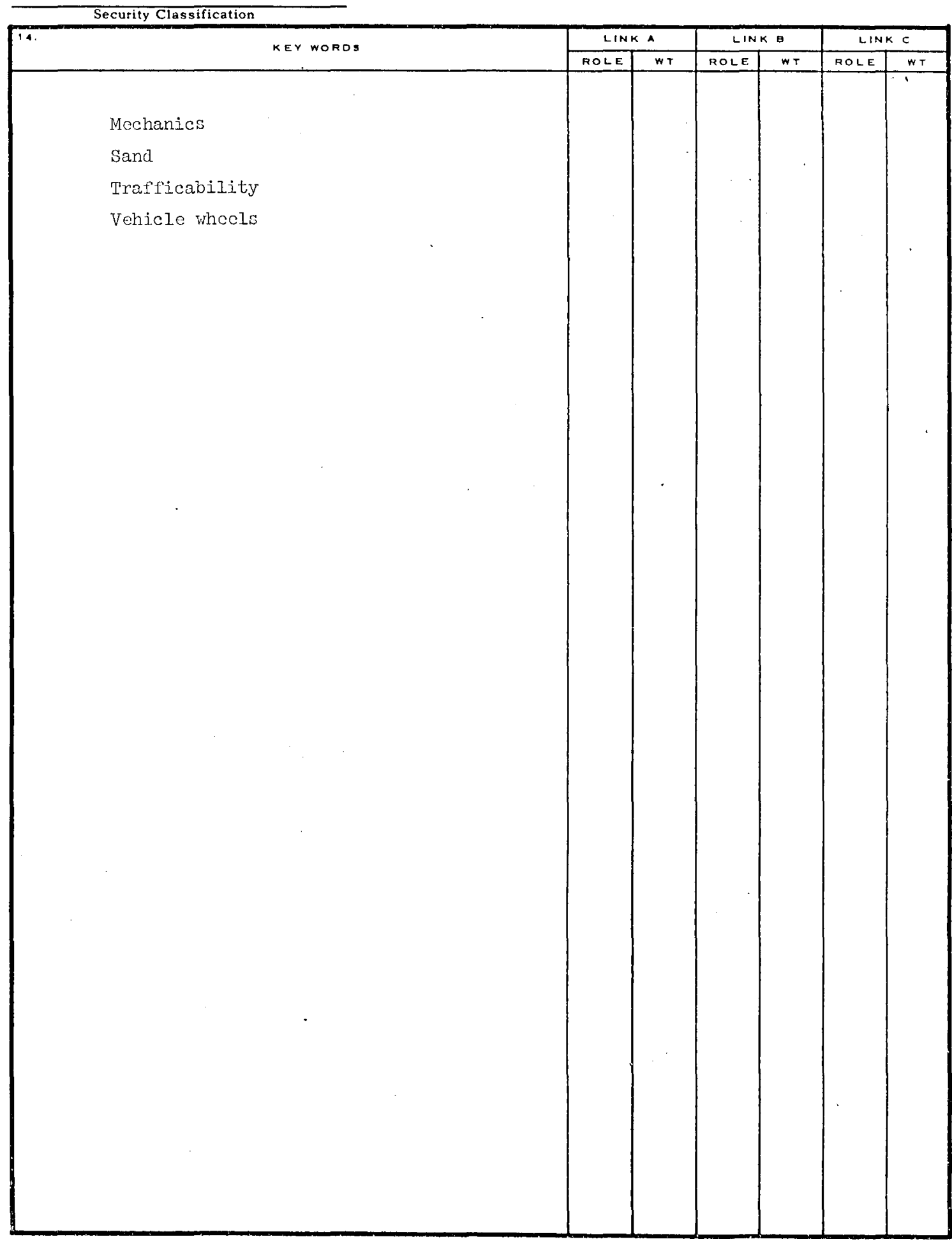

Unclassified 
